\title{
Measurement of Droplet Size in Sprinkler Sprays
}
J. R. Lawson
W. D. Walton
D. D. Evans

\section{U.S. DEPARTMENT OF COMMERCE National Bureau of Standards National Engineering Laboratory Center for Fire Research Gaithersburg, MD 20899}

February 1988

Supported in part by:

The Swedish Fire Research Board Stockholm, Sweden

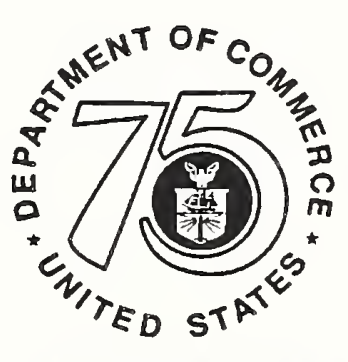

and 



\section{MEASUREMENT OF DROPLET SIZE IN SPRINKLER SPRAYS}
J. R. Lawson
W. D. Walton
D. D. Evans

U.S. DEPARTMENT OF COMMERCE

National Bureau of Standards

National Engineering Laboratory

Center for Fire Research

Gaithersburg, MD 20899

February 1988

Supported in part by:

The Swedish Fire Research Board

Stockholm, Sweden

and

General Services Administration

Washington, DC

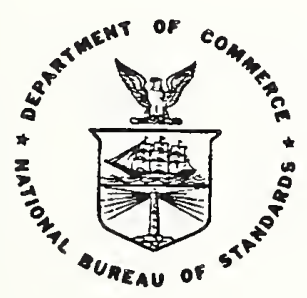

U.S. DEPARTMENT OF COMMERCE, C. William Verity, Secretary NATIONAL BUREAU OF STANDARDS, Ernest Ambler, Director 

List of Tables. . . . . . . . . . . . . . . . . . . . . . . iv

List of Figures . . . . . . . . . . . . . . . . . . . . . . . . . v

Abstract . . . . . . . . . . . . . . . . . . . . . . . 1

1. INTRODUCTION . . . . . . . . . . . . . . . . . . . . . . . . 2

2. TEST APPARATUS AND DROPLET MEASUREMENT . . . . . . . . . . . . . . . . 3

3. APPARATUS CALIBRATION . . . . . . . . . . . . . . . . . . . . . . 4

4. TEST PROCEDURE . . . . . . . . . . . . . . . . . . . . . . . . 5

5. TEST RESULTS . . . . . . . . . . . . . . . . . . . . . . 6

6. DROPLET SIZE' COMPARISON AND ANALYSIS . . . . . . . . . . . . . . . . . 7

6.1 MANUAL MEASUREMENTS . . . . . . . . . . . . . . . . . . . 7

6.2 RESULTS OF COMPARISON . . . . . . . . . . . . . . . . . . . . . . . . . . 8

6.3 COMPARISON OF RESULTS WITH OTHER DATA . . . . . . . . . . . . . . 9

7. SUMMARY . . . . . . . . . . . . . . . . . . . . . . 11

8. ACKNOWLEDGEMENTS . . . . . . . . . . . . . . . . . . . . . . . . . . 13

9. REFERENCES . . . . . . . . . . . . . . . . . . . . . . . . . . 14 
List of Tables

Page

Table 1: Summary of test results . . . . . . . . . . . . . . . . 15. 
Figure 1. Photograph of strobe/camera module and sprinkler head . . . . 16

Figure 2. Photograph of sprinkler head under test . . . . . . . . . . . . 17

Figure 3. Photograph of video screen showing water droplets . . . . . . . 18

Figure 4. Analyzer field orientation . . . . . . . . . . . . . . . . . . 19

Figure 5. Test volume . . . . . . . . . . . . . . . . . . . . . . 20

Figure 6. Radial test positions . . . . . . . . . . . . . . . . . . . . 20

Figure 7. Terms used to define analyzer position relative to sprinkler . 21

Figure 8. Vertical and horizontal test positions . . . . . . . . . . . . 22

Figure 9. Normalized cumulative volume and cumulative number vs. diameter, Test No. $1\left(1 \mathrm{l} / \mathrm{s}, 90^{\circ}, 90^{\circ}\right)$. . . . . . . . . . . . 23

Figure 10. Normalized cumulative volume and cumulative number vs.

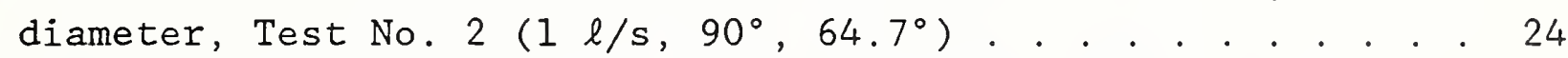

Figure 11. Normalized cumulative volume and cumulative number vs.

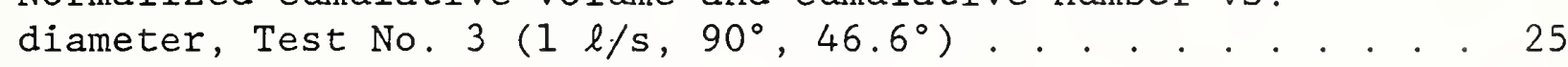

Figure 12. Normalized cumulative volume and cumulative number vs. diameter, Test No. $4\left(1 \mathrm{l} / \mathrm{s}, 90^{\circ}, 27.9^{\circ}\right)$. . . . . . . . . . . 26

Figure 13. Normalized cumulative volume and cumulative number vis. diameter, Test No. $5\left(1 \mathrm{l} / \mathrm{s}, 90^{\circ}, 0^{\circ}\right)$

Figure 14. Normalized cumulative volume and cumulative number vs. diameter, Test No. $6\left(2 \mathrm{l} / \mathrm{s}, 90^{\circ}, 90^{\circ}\right)$. . . . . . . . . . . 28

Figure 15. Normalized cumulative volume and cumulative number vs. diameter, Test No. $7\left(2 \mathrm{l} / \mathrm{s}, 90^{\circ}, 64.7^{\circ}\right)$. . . . . . . . . . . 29

Figure 16. Normalized cumulative volume and cumulative number vs. diameter, Test No. $8\left(2 \mathrm{l} / \mathrm{s}, 90^{\circ}, 46.6^{\circ}\right)$. . . . . . . . . . 30

Figure 17. Normalized cumulative volume and cumulative number vs. diameter, Test No. $9\left(2 \mathrm{l} / \mathrm{s}, 90^{\circ}, 27.9^{\circ}\right)$. . . . . . .

Figure 18. Normalized cumulative volume and cumulative number vs. diameter, Test No. $10\left(2 \mathrm{l} / \mathrm{s}, 90^{\circ}, 0^{\circ}\right)$. . . . . . . . . . . . 32

Figure 19. Normalized cumulative volume and cumulative number vs.

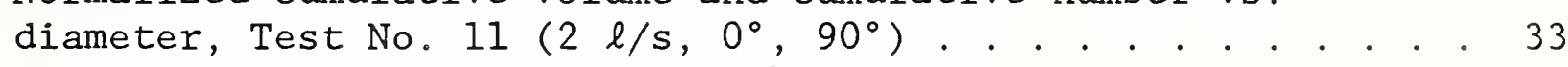

Figure 20. Normalized cumulative volume and cumulative number vs. diameter, Test No. $12\left(2 \mathrm{l} / \mathrm{s}, 0^{\circ}, 64.7^{\circ}\right)$. . . . . . . . . . . 34

Figure 21. Normalized cumulative volume and cumulative number vs.

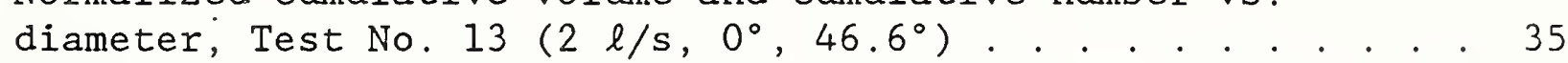

Figure 22. Normalized cumulative volume and cumulative number vs. diameter, Test No. $14\left(2 \mathrm{l} / \mathrm{s}, 0^{\circ}, 27.9^{\circ}\right)$. . . . . . . . . . . 36

Figure 23. Normalized cumulative volume and cumulative number vs. diameter, Test No. $15\left(2 \mathrm{l} / \mathrm{s}, 0^{\circ}, 0^{\circ}\right)$

Figure 24. Aggregate normalized cumulative volume and cumulative number vs. diameter for Tests No. $1-5,(2 \mathrm{l} / \mathrm{s}) . . .9 . .938$

Figure 25. Aggregate normalized cumulative volume and cumulative number vs. diameter for Tests No. $6-10(2 \mathrm{l} / \mathrm{s})$. . . . . . . 39

Figure 26. Aggregate normalized cumulative volume and cumulative number vs. diameter for Tests No. $11-15(2 \mathrm{l} / \mathrm{s})$. . . . . 40

Figure 27. Normalized cumulative volume and cumulative number vs. diameter for droplets captured in oil Test No. $1(1 \mathrm{l} / \mathrm{s}) . .41$

Figure 28. Normalized cumulative volume and cumulative number vs. diameter for droplets captured in oil Test No. $2(2 \mathrm{l} / \mathrm{s})$ 
Figure 29. Experimental verification of $W_{e}^{-1 / 3}$ prediction

for water spray nozzles . . . . . . . . . . . . . . . . . 43

Figure 30. Volume median diameter vs. position angle . . . . . . . . . 44 


\section{Abstract}

A computer controlled video shadowgraph was used to collect data on the spray characteristics of a commercially available sprinkler head. A total of 15 tests were carried out that measured spray characteristics at different positions close to the sprinkler head. Tests were conducted using two different water flow rates, one and two liters per second. Droplet diameters were measured and analyzed to produce graphic presentations of normalized cumulative volume and cumulative number vs. droplet diameter data. In addition, a comparison was made between the droplet diameters measured using the video analyzer and droplet samples collected in a light oil and measured manually using a microscope. The data are also compared with results found in the literature. Data on more than 66,000 spray droplets were collected and used for analysis in the development of this report.

Keywords: Drop size measurements, droplets, water sprays, sprinkler heads, sprinkler systems. 


\section{INTRODUCTION}

Fire growth and extinction in a structure embodies the interaction of many complex phenomena that are becoming better understood through research efforts at the National Bureau of Standards and other fire research facilities around the world. As part of this increased knowledge, methods for estimating the influence of water sprays on fires and extinguishment have evolved. Several computer models have been developed in the fire research community that address the interaction of water sprays with fire driven flows [1,2]. Each of these computer models, as well as other analysis of heat and mass transfer effects between sprays and hot gas flows, require accurate input data characterizing water droplets that are generated by a common sprinkler head. Water droplet size distribution from a sprinkler head can greatly change the characteristics of fire growth and the transport of hot gases within structures. The data gathered during this study is designed to provide some of the information necessary to exercise these computer models. 


\section{TEST APPARATUS AND DROPLET MEASUREMENT}

The test apparatus used in this study is a commercial instrument produced by Bete Fog Nozzle Inc. ${ }^{1}$ The apparatus used is a computer controlled video shadowgraph. This equipment is controlled by custom software used to accurately measure droplet size in a sprinkler spray. The apparatus consists of four major components: the computer, video analyzer, video camera, and high intensity strobe system [3]. ${ }^{2}$ The strobe and video camera module is shown in Figure 1. The photograph in Figure 2 shows an example of the analyzer with a sprinkler head being tested.

The video camera is used to capture water droplet shadow images produced by a high intensity strobe fired on the other side of the sample volume. See Figure 3. Image data from each video frame is stored in a computer file for processing after a multi-frame test is completed. Droplet shadow area is determined by multiplying the number of video pixels per drop by a calibration constant which depends on the magnification used. The reported diameter for the droplet is the diameter of a circle that has the same projected area as the measured image. Thus non-circular images resulting from the image of non-spherical drops are reported as effective spherical diameters. The

1 Certain commercial equipment, instruments, or materials are identified in this paper in order to adequately specify the experimental procedure. Such identification does not imply recommendation or endorsement by the National Bureau of Standards.

Neither the contents of this report nor the fact that the tests were made at the National Bureau of Standards shall be used for advertising or promotional purpose. report.

2 Figures in brackets indicate literature references at the end of this 
droplet analyzer can measure droplets over a range from 3 microns, $\mu \mathrm{m}$, to more than $21,000 \mu \mathrm{m}(21 \mathrm{~mm})$ by installing various optical lenses [3]. The size range for droplets of interest in this study was from 100 to $2000 \mu \mathrm{m}(0.1$ to $2.0 \mathrm{~mm}$ ). Information on optics selection for the above droplet size range is contained in section 3 .

\section{APPARATUS CALIBRATION}

Before any tests are conducted, the test apparatus must be properly configured and calibrated to insure that accurate test data are generated. It is important that proper camera lenses be selected for the droplet analyzer when a particular droplet size range is being studied. In this test program, measurement of water droplet diameters as large as $2000 \mu \mathrm{m}$ were required. The camera lens combination adopted for these tests provided a magnification of approximately 1.1 power which permitted resolution of drops as small as $100 \mu \mathrm{m}$ and as large as $2000 \mu \mathrm{m}$. The sample field of view, as shown in Figure 4, for this optical arrangement was experimentally measured by positioning a target within the video field and moving it from side to side and up and down. Figure 5 shows the sampling volume used in these tests. The field of view provided by the lens combination used in this study was $21.7 \mathrm{~mm}$ wide and $17.3 \mathrm{~mm}$ high and approximately $5 \mathrm{~mm}$ depth. Droplets were admitted into the sampling volume through two vanes separated by $5 \mathrm{~mm}$ and located at a $77 \mathrm{~mm}$ radius from the center of the sampling volume. Thus, all drops measured may be considered as traveling perpendicular to the direction of illumination used to form the shadowgraphic images on the video display. 
Calibration of distances and pixel area on the video image was accomplished by measuring balls of known diameter placed in the measurement volume. Software calibration constants were entered into the image analysis program based on these measurements.

\section{TEST PROCEDURE}

In order to characterize the spray from a selected nominal $15 \mathrm{~mm}$ diameter pendent sprinkler head, water droplets were measured at several locations parallel and perpendicular to the sprinkler frame arms (Figure 6). Before testing, one of the sprinkler frame arms was marked and designated 0 degrees cylindrical angle. Other terms used to identify analyzer position relative to the sprinkler head are centerline coordinate, radial coordinate, distance from nozzle and azimuthal angle. All terms are defined by the sketches in Figure 7.

The droplet analyzer was used to make measurements at five positions with a 0 degree orientation relative to the sprinkler head. The sprinkler head was then turned 90 degrees relative to the analyzer and another series of tests was conducted. During the test program, the analyzer was never placed closer than $240 \mathrm{~mm}$ from the sprinkler head in order to stay just beyond sheet breakup of the water spray. Figure 8 describes the test measurement locations.

A total of ten tests were conducted at the position 90 degrees to the frame arms, five tests at a flow rate of one liter per second and five tests at a 
flow rate of two liters per second. All five tests at the 0 degree position were made with a water flow rate of two liters per second.

\section{TEST RESULTS}

The results of the fifteen tests are summarized in Table 1 . Given in the table for each test is the flow rate, cylindrical angle (Figure 7) and position angle (Figure 8). Table 1 includes the number of frames per test, total number of drops analyzed, mean droplet diameter, volume mean diameter, median diameter, volume median diameter and the total droplet volume for each of the tests. The mean diameter is the sum of the diameters divided by the number of drops. The volume mean diameter is the diameter of a drop whose volume is the sum of the volumes of all of the drops divided by the number of drops. The median diameter is the diameter of a drop for which half of the drops have a larger diameter and half a smaller diameter. The volume median diameter is the diameter of a drop for which all of the drops larger than that diameter have an aggregate volume equal to half of the total volume of all of the drops.

Plots of the size distributions have been given for each of the tests in Figures 9 - 23. The plot for the positions measured shows the cumulative number and cumulative volume vs. diameter information normalized using the total number of drops measured and the total volume of the drops measured respectively. The median drop diameter and volume median diameter can be read directly at 0.5 on the ordinate. The average diameter and average volume diameter are indicated on the respective curves. Figures 24 - 26 are 
aggregate information for each of the three flow rate, cylindrical angle combinations. These plots show the combined distributions over the five position angles measured in each case.

\section{DROPLET SIZE COMPARISON AND ANALYSIS}

Both manually measured droplets from the sprinkler spray and comparisons with available published data were made as checks on the automated analysis.

\subsection{MANUAL MEASUREMENTS}

A $89 \mathrm{~mm}$ wide by $19 \mathrm{~mm}$ deep glass petri dish with a cover was used to collect the water droplet samples from the water spray emitted from the test sprinkler head. The petri dish was half filled with pharmacy grade castor oil (oleum ricini). The cover was placed on the dish until it was opened at the desired location in the water spray. Droplets were allowed to collect in the oil for about one second, and then the cover was placed back on the petri dish. The dish was removed from the spray field, and the exterior was dried. The cover was removed, and the dish containing the oil and water droplets was placed under a microscope. The microscope eyepiece had a calibrated graduated scale that was used for measuring the water droplets. The scale was calibrated using a precision microscope slide with circular dots of known size. A sample of as many as 55 droplets was measured from each specimen taken. The largest and smallest drops were cataloged for each petri dish specimen. Samples were taken with water flow rates of one and two liters per second. 


\subsection{RESULTS OF COMPARISON}

One sample was taken on a horizontal plane at a location with a cylindrical angle of $90^{\circ}$ to the sprinkler frame arms and position angle of $90^{\circ}$ from the sprinkler head. This corresponds to the position measured in test 1 , Figure 9. Water flow rate for this sample was one liter per second. From this sample, a total of 53 droplets were measured. The diameter of the largest droplet measured was $1261 \mu \mathrm{m}$ and the smallest was $90 \mu \mathrm{m}$. The $90 \mu \mathrm{m}$ value represents the limit of resolution for the microscopic measurement. The mean volume diameter was $465 \mu \mathrm{m}$. This sample compares well with the mean volume diameter obtained from the same sprinkler spray location in test 1. The mean volume diameter measured by the droplet analyzer for that test was $451 \mu \mathrm{m}$. This is a difference of less than 4 percent. Figure 27 provides plots of normalized cumulative number and normalized cumulative volume vs. diameter for the 53 droplet sample taken in oil. These distributions show good agreement with those of test 1 .

The water flow rate was changed to two liters per second, and another spray sample was taken at a position located approximately $240 \mathrm{~mm}$ below and $254 \mathrm{~mm}$ away from the sprinkler head centerline. This corresponds to the position examined in test 8 , shown in Figure 16. The sample was again taken perpendicular to the sprinkler frame. In this sample 55 droplets were measured. The droplet diameters ranged from 90 to $720 \mu \mathrm{m}$ with a mean volume diameter of $308 \mu \mathrm{m}$. The mean volume diameter determined by the analyzed in test 8 at the same location was $385 \mu \mathrm{m}$. These results represent a difference of only 25 percent between manual and automated measurements. Figure 28 
provides plots of normalized cumulative number and normalized cumulative volume vs. diameter for the 55 droplet sample in oil. These plots when compared to those of test 8 (Figure 16) do not agree as well as those the previous set. This is primarily due to the relative lack of large droplets in this samplecollected manually.

\subsection{COMPARISON OF RESULTS WITH OTHER DATA}

Correlations of spray droplet diameters for several commercial sprinklers have been reported by Dundas [4].

The correlation of data from the Dundas' study is shown in Figure 29. The data from this study are presented along with data from Dundas [4], Braidech and Neale [5], and Kroesser [6] as the dimensionless droplet diameter (median volume diameter divided by sprinkler orifice diameter) plotted as a function of Weber Number $\left(W_{e}\right)$.

$$
\mathrm{d}_{\mathrm{m}} / \mathrm{d} \propto \mathrm{W}_{\mathrm{e}}=\left(\rho \mathrm{u}^{2} \mathrm{~d} / \sigma\right)
$$

where:

$$
\begin{aligned}
& \mathrm{d}=\text { sprinkler orifice diameter } \\
& \mathrm{d}_{\mathrm{m}}=\text { volume median diameter of water droplets } \\
& \mathrm{u}=\text { velocity of water flow at the sprinkler orifice } \\
& \rho=\text { water density } \\
& \sigma=\text { surface tension of water-air interface }
\end{aligned}
$$


The data from this study has been reduced to three points representing the aggregate analysis which combines all the data from the different position angles measured at the separate flow rates and cylindrical angles. Notice each of these three points is the result of analysis performed on $20,000-25,000$ droplet diameter measurements!

Figure 30 shows all 15 measured volume median droplet diameters vs. position angle points. Directly under the sprinkler is referred to as the $0^{\circ}$ position angle, while the $90^{\circ}$ position angle is in the plane of the sprinkler deflector plate. For the two sets of data at $90^{\circ}$ cylindrical angle, which is perpendicular to the plane of the frame arms, the lower flow rate produces larger volume median droplet diameters as would be expected. However, what appears to be an outlier data point at $46.6^{\circ}$ position angle and $1232 \mu \mathrm{m}$ diameter is actually quite close to the expected variation between the $1 \mathrm{l} / \mathrm{s}$ and $2 \mathrm{l} / \mathrm{s}$ flow rates based on $\mathrm{W}_{\mathrm{e}}^{-1 / 3}$ variations. The expected ratio of volume median diameter for the low flow rate to high flow rate is:

$$
\begin{gathered}
\frac{D_{m}(1 \ell / s)}{D_{m}(2 \ell / s)}=\left(\frac{W_{e}(1 \ell / s)}{W_{e}(2 \ell / s)}\right)^{-1 / 3}=\left(\frac{16200}{64800}\right)^{-1 / 3} \\
\frac{D_{m}(1 \ell / s)}{D_{m}(2 \ell / s)}=1.59
\end{gathered}
$$

The measurement values at $46.6^{\circ}$ position angle are $1232 \mu \mathrm{m}$ for the $1 \mathrm{l} / \mathrm{s}$ flow rate and $736 \mu \mathrm{m}$ for the $2 \mathrm{l} / \mathrm{s}$ flow rate. The ratio is 1.67 , which is close to the expected result. It follows, the "agreement" in four other position 
angles measured between the two flow rates at the $90^{\circ}$ cylindrical angle are actually unexpected results.

Measurements in the plane of the frame arms ( $0^{\circ}$ cylindrical angle) show a deficit of large drops over the mid-range of position angles from $40^{\circ}$ to $70^{\circ}$. This is the result of the frame arms blocking the flow.

For a spray as complex and non-uniform as that from a common fire protection sprinkler, there are considerable changes in spray pattern when the flow rate is doubled. This diminishes the values of detailed spatial comparisons as presented in Figure 30 and supports use of aggregate quantities such as those found in Figure 29 which average over the spray pattern from the sprinklers.

\section{SUMMARY}

A series of experiments was carried out to measure and collect information on sprinkler head spray characteristics. A computer driven video shadowgraph technique to collect water droplet data on the sprinkler head sprays was used. The data were reduced, analyzed and compared with other existing data. This data comparison showed good agreement. Water droplets were also collected using castor oil and then measured using a microscope. The comparison of droplet analyzer distributions obtained from the analyzer with those calculated from manual sizing of a small number of drops collected in caster oil showed very good agreement in one of two cases. The data generated during this study was collected and presented in a manner that would allow it to be used in the evaluation of sprinkler heads or to be use in development of fire 
growth and extinguishment computer models. Values of median volume diameter averaged over portions of the spray agreed well with previously measured values for commercial sprinklers when correlated by the Weber number. For the $15 \mathrm{~mm}$ pendent sprinkler with an $11 \mathrm{~mm}$ orifice diameter, median volume diameters of $943 \mu \mathrm{m}$ and $703 \mu \mathrm{m}$ were found for $1 \mathrm{l} / \mathrm{s}$ and $2 \mathrm{l} / \mathrm{s}$ flow rates respectively at positions in the spray perpendicular to the plane of the frame arms. The median volume diameter decreased to $575 \mu \mathrm{m}$ in the plane of the frame arms at a flow rate of $2 \mathrm{l} / \mathrm{s}$. 


\section{ACKNOWLEDGEMENTS}

Appreciation is extended to Mr. Emil Braun of the Center for Fire Research for his assistance in developing the data transfer routines used in this project and helping with other computer related efforts. Mr. Paul Bennett of Autodata Engineering Software is recognized for his assistance in creating a unique computer program for collecting and displaying test data from the droplet analyzer. The management and technical staff of Bete Fog Nozzle Inc. provided advice and assistance on experimental technique and equipment throughout the project. 


\section{REFERENCES}

[1] Alpert, R. L., Delichatsios, M. M., Calculated Interaction of Water Droplet Sprays With Plumes in Compartments, NBS-GCR-86-520, National Bureau of Standards, U.S.A., 1986.

[2] Ball, J. A., Pietrzak, L. M., Investigation to Improve the Effectiveness of Water in the Suppression of Compartment Fires, Fire Research, 1, No. 4/5, Netherlands, $1977-78$.

[3] Droplet Analyzer System Operators Manual, Bete Fog Nozzle Inc., Greenfield, MA (1985).

[4] Dundas P.H., THe Scaling of Sprinkler Discharge: Prediction of Drop Size, Progress Report No. 10, FMRC Serial No. 18792, RC73-T-40, Factory Mutual Research Corporation, Norwood, Massachusetts, 1974.

[5] Braidech, M.M. and Neale, J.A., "The Mechanism of Extinguishment of Fire by Finely Divided Water", NBFU Research Report No. 10, Underwriters' Laboratories, Inc., 1955.

[6] Kroesser, F.W., "The Measurement of Drop Sizes Produced by the Discharge of Water From a Sprinkler", FMRC Serial 18792 Technical Report, August 1969. 


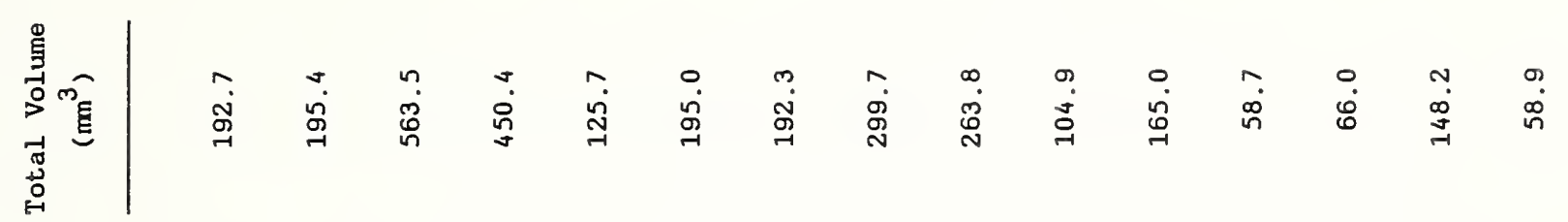

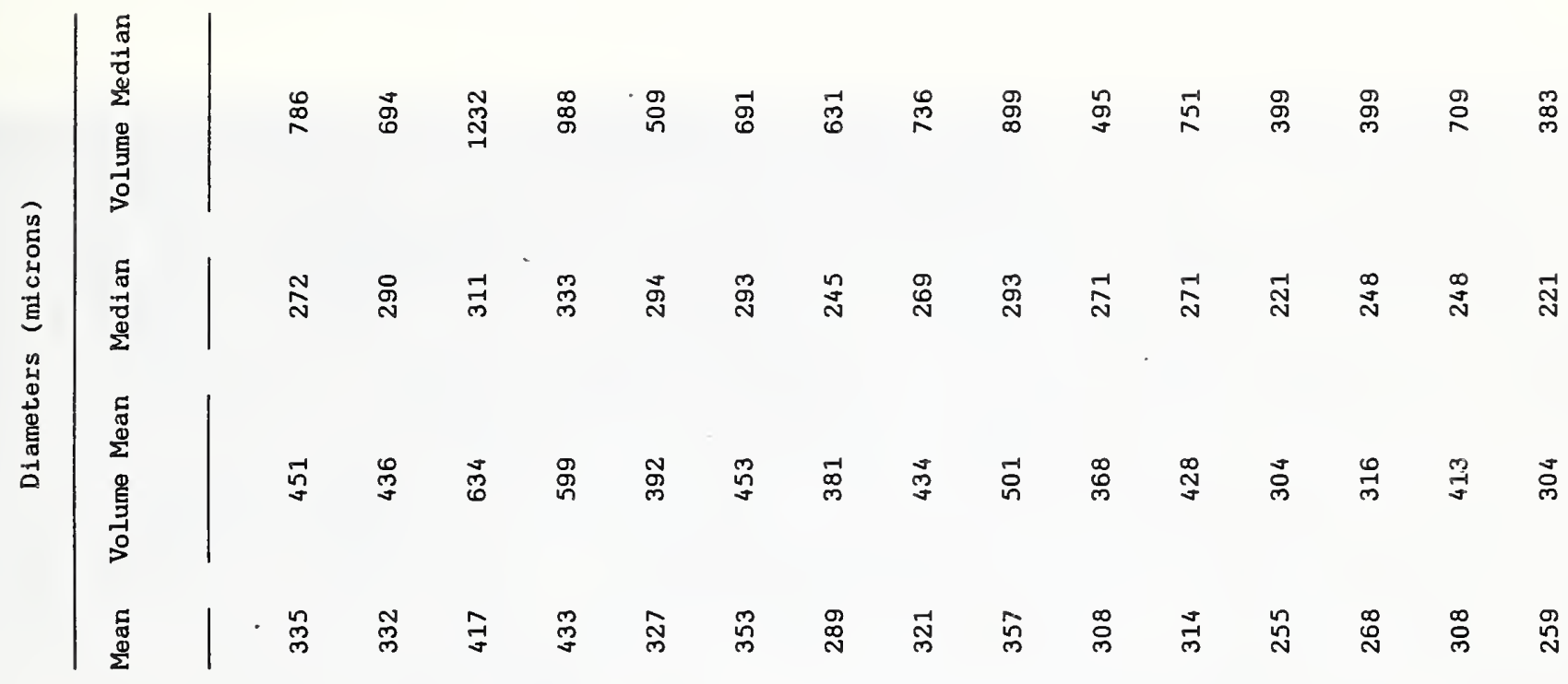
草|

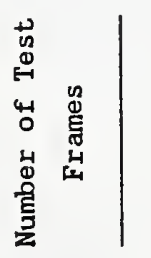

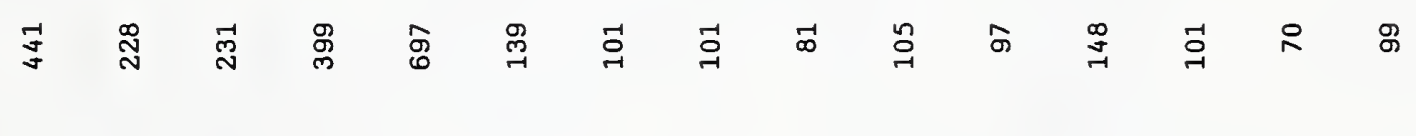
要要

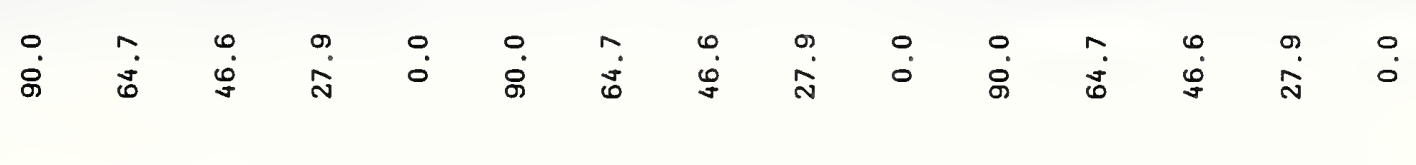
焉| ○

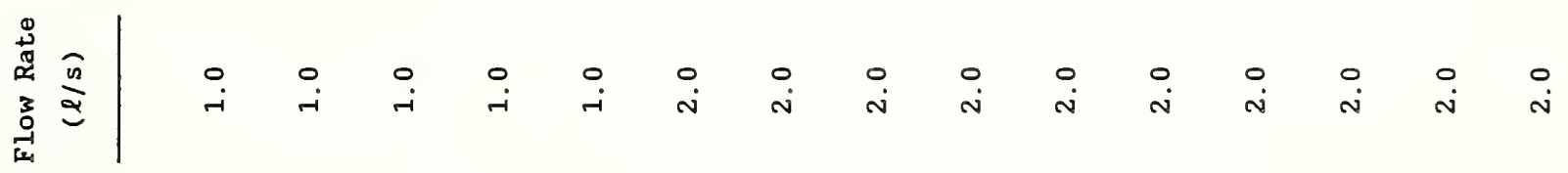

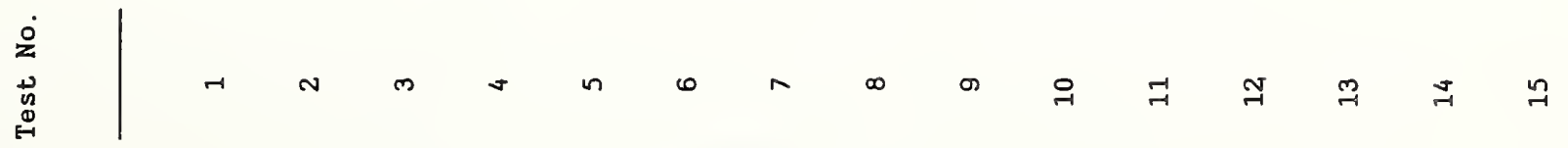




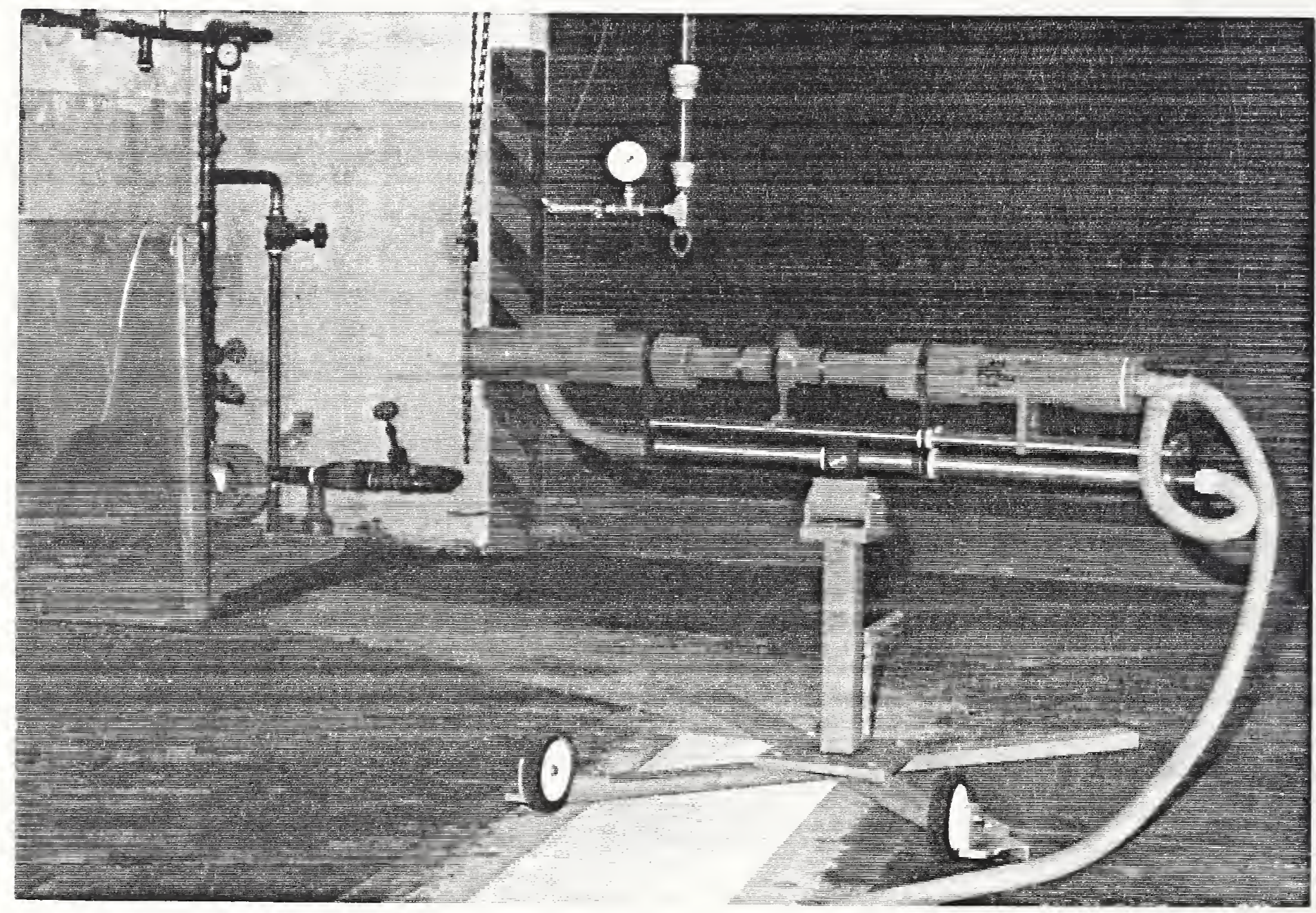

Figure 1. Photograph of strobe/camera module and sprinkler head 


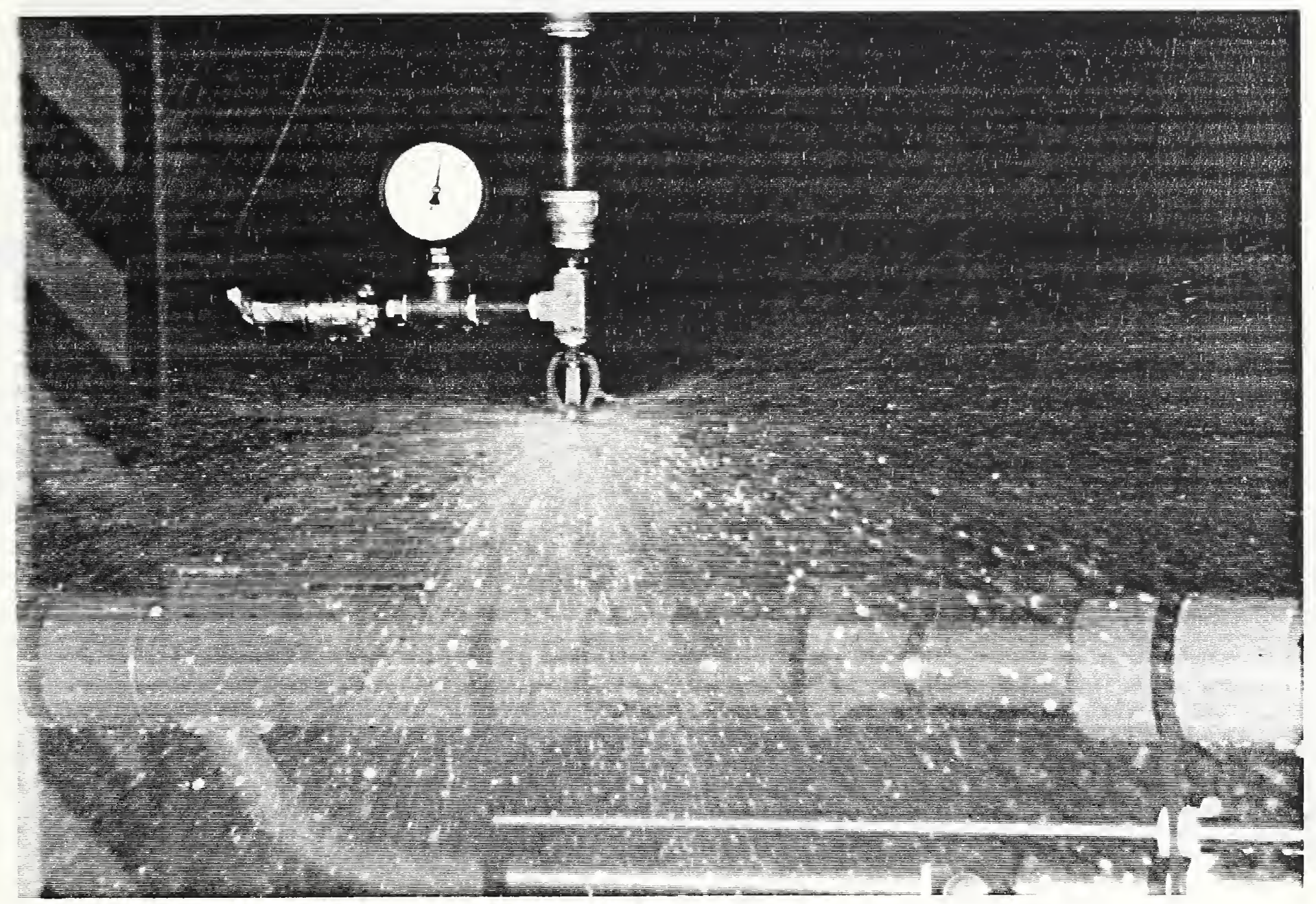

Figure 2. Photograph of sprinkler head under test 


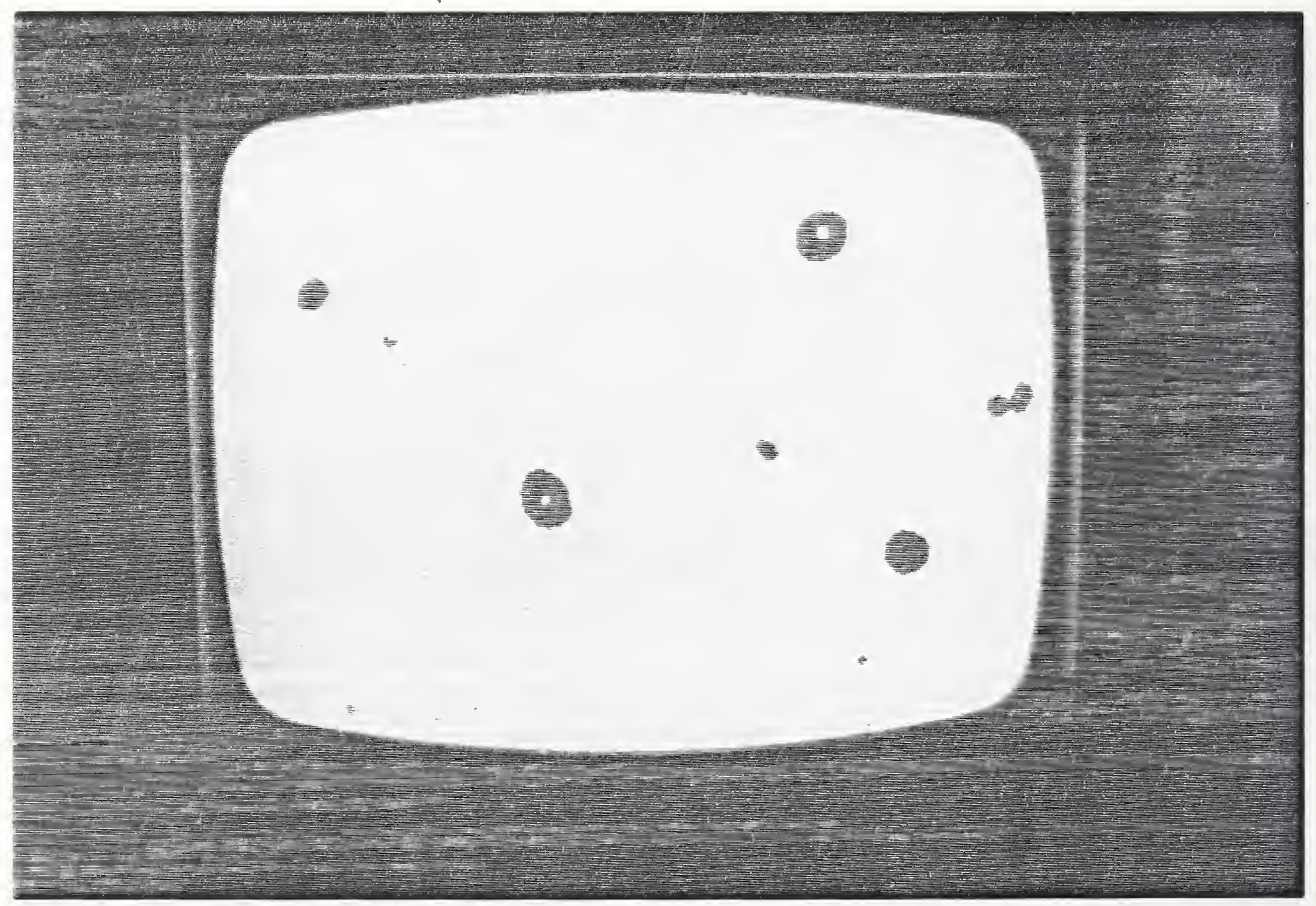

Figure 3. Photograph of video screen showing water droplets 


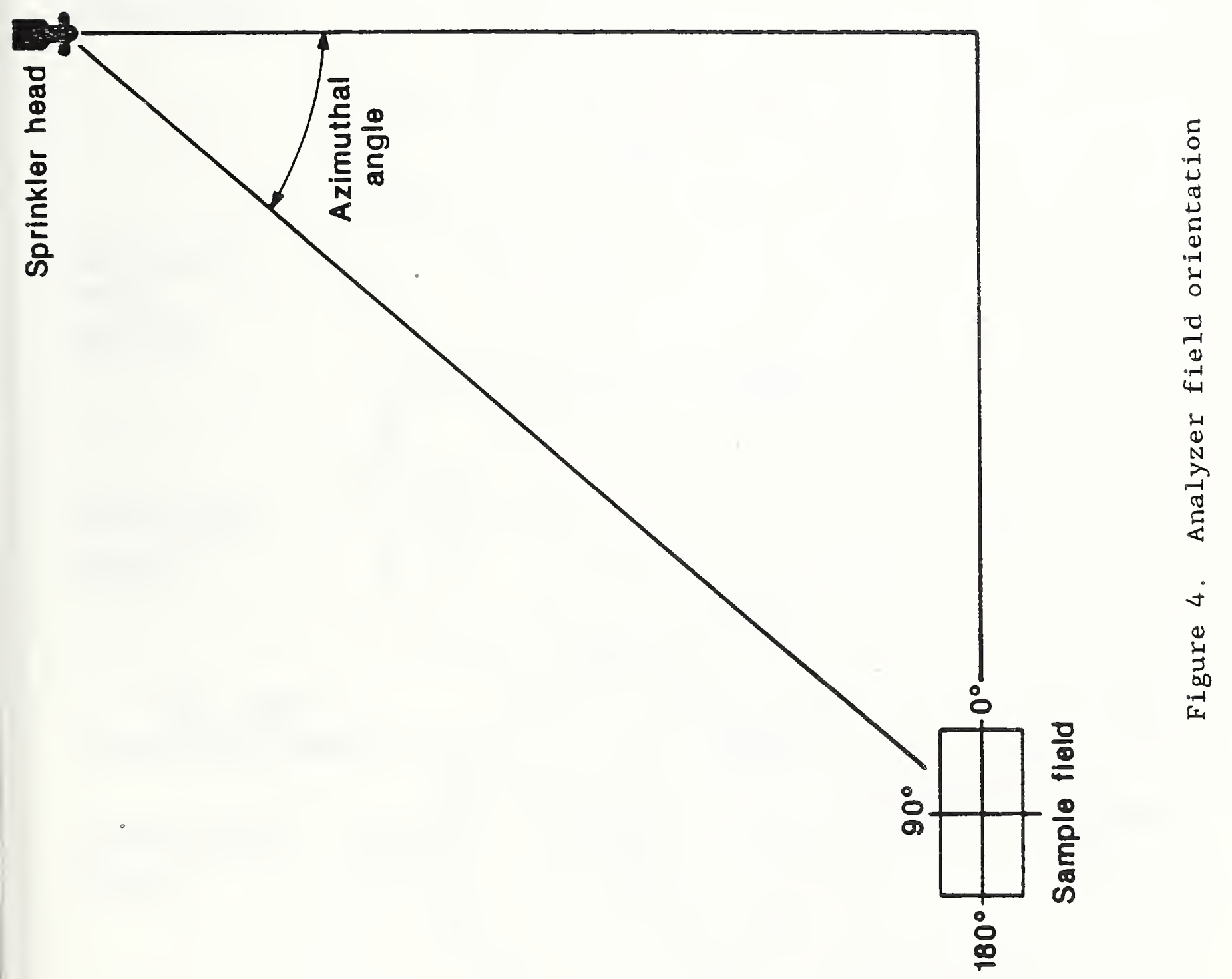




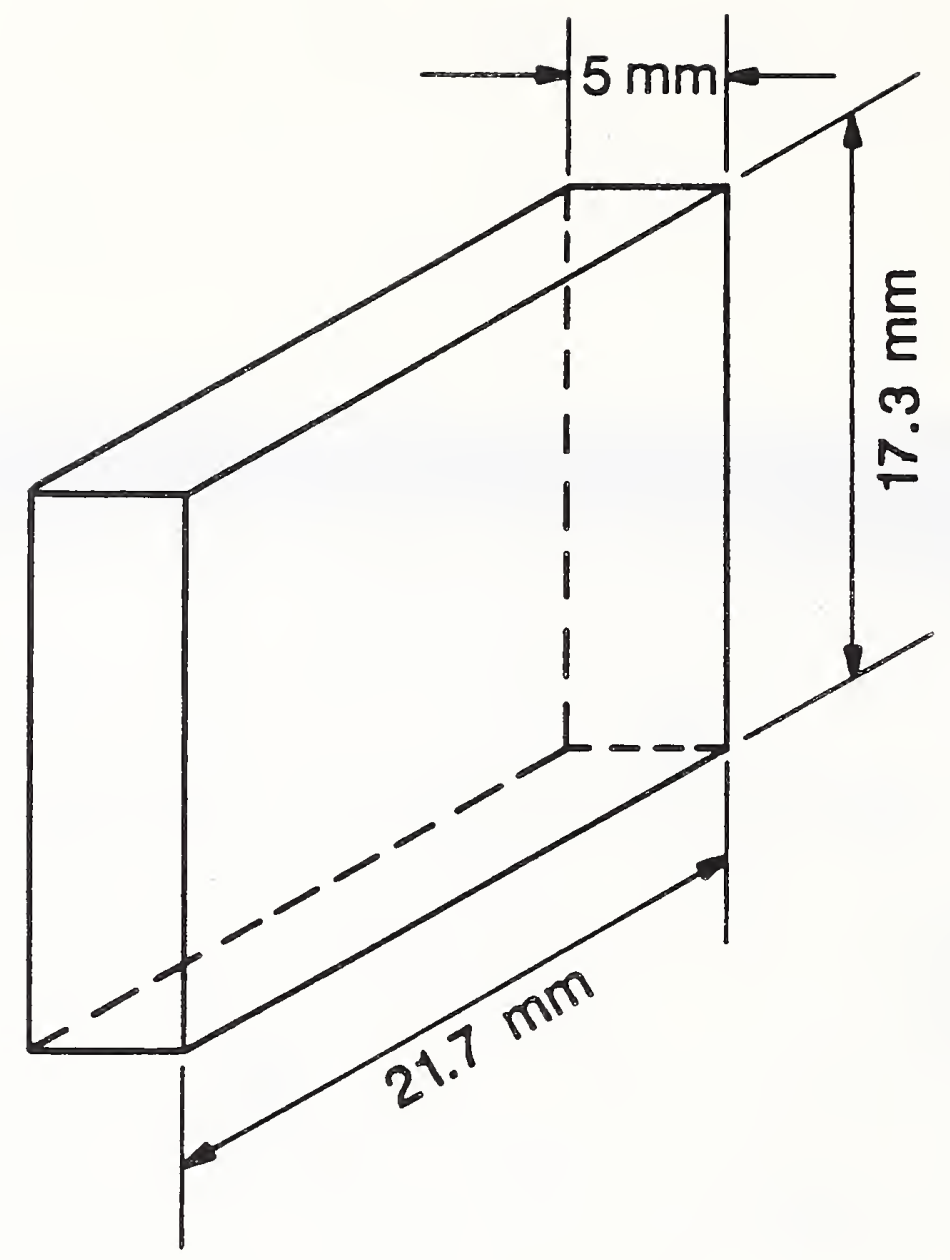

Figure 5: Test volume.

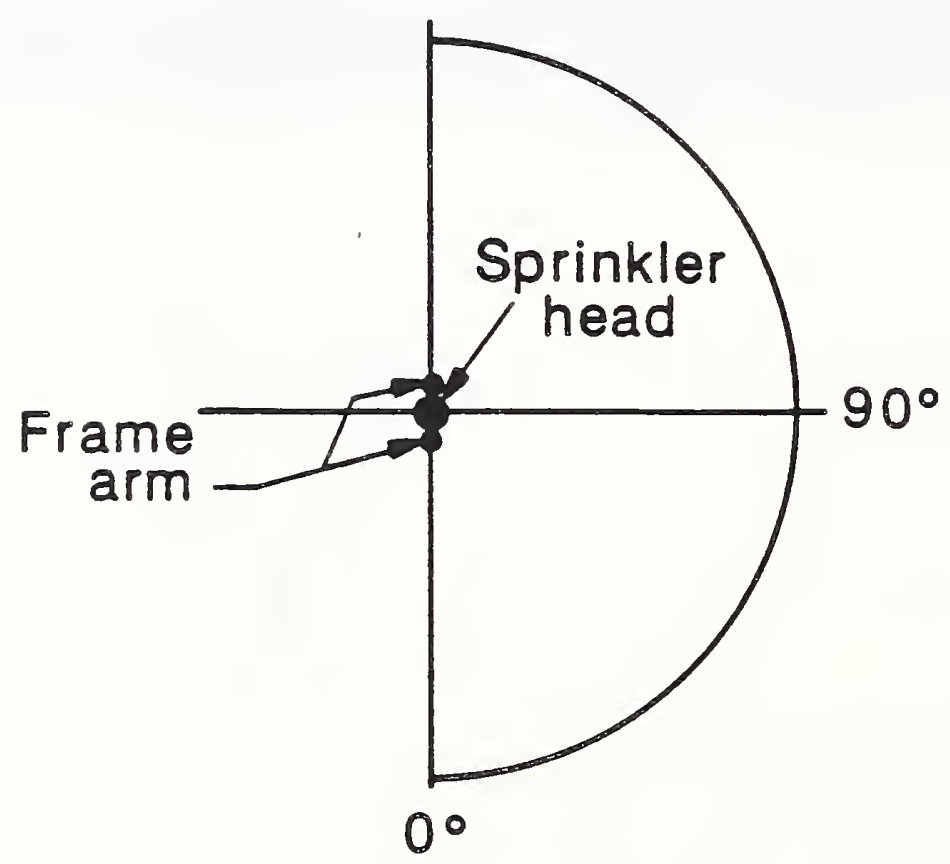

Figure 6: Radial test positions. 


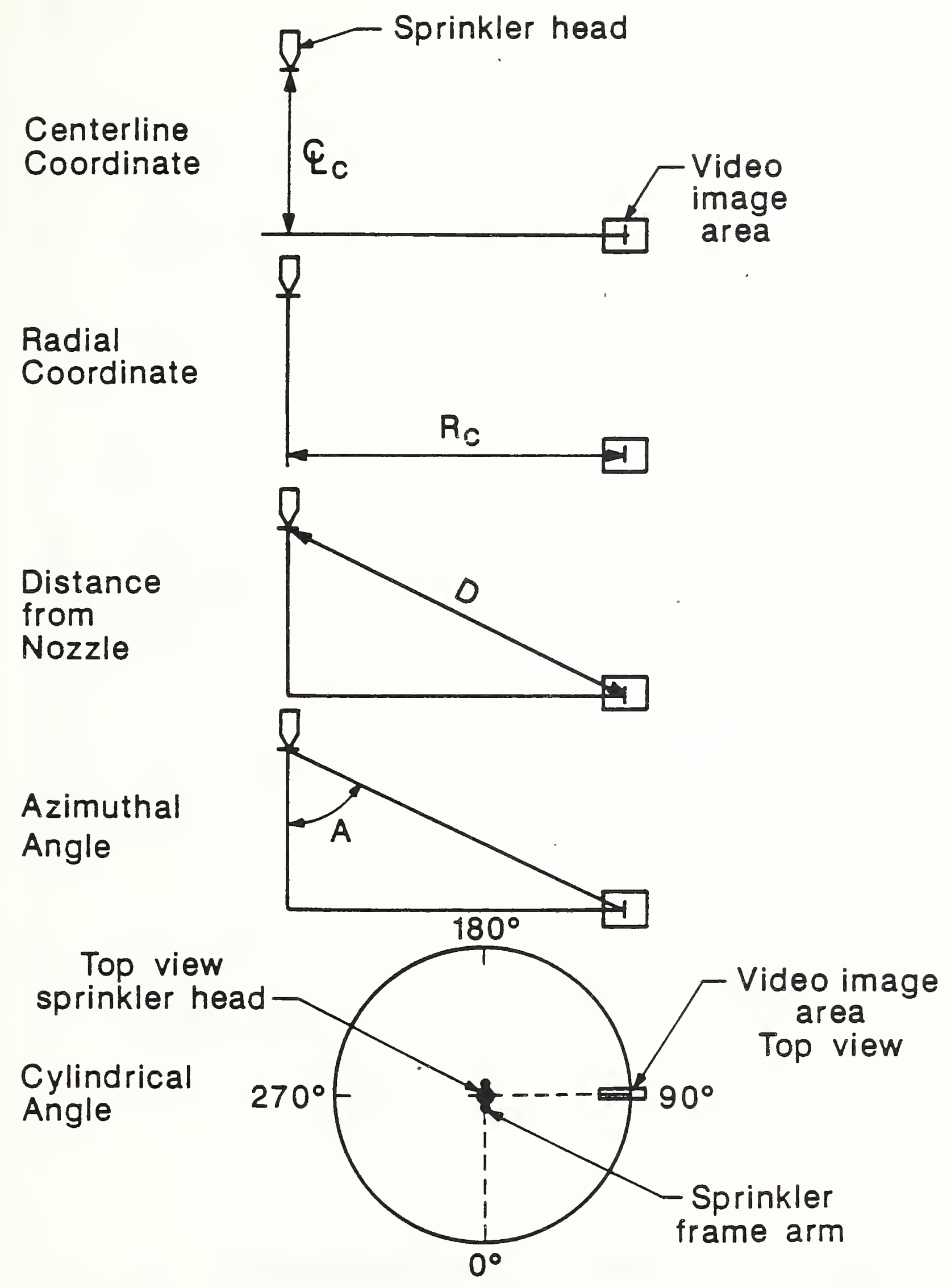

Figure 7. Terms used to define analyzer position relative to sprinkler. 


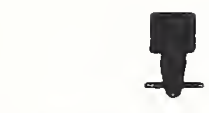

Sprinkler head

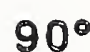

to

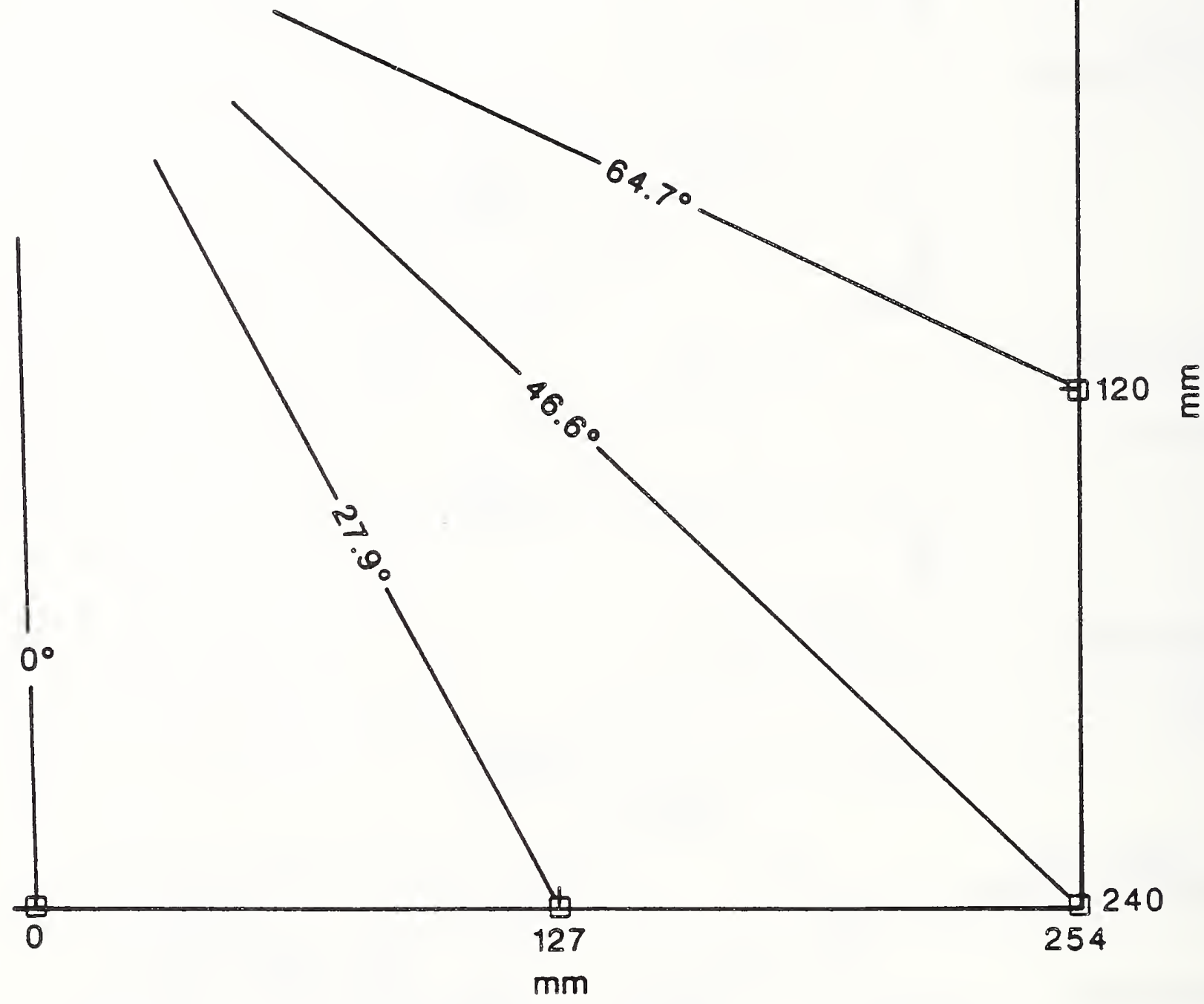

Figure 8: Vertical and horizontal test positions. 
监崖
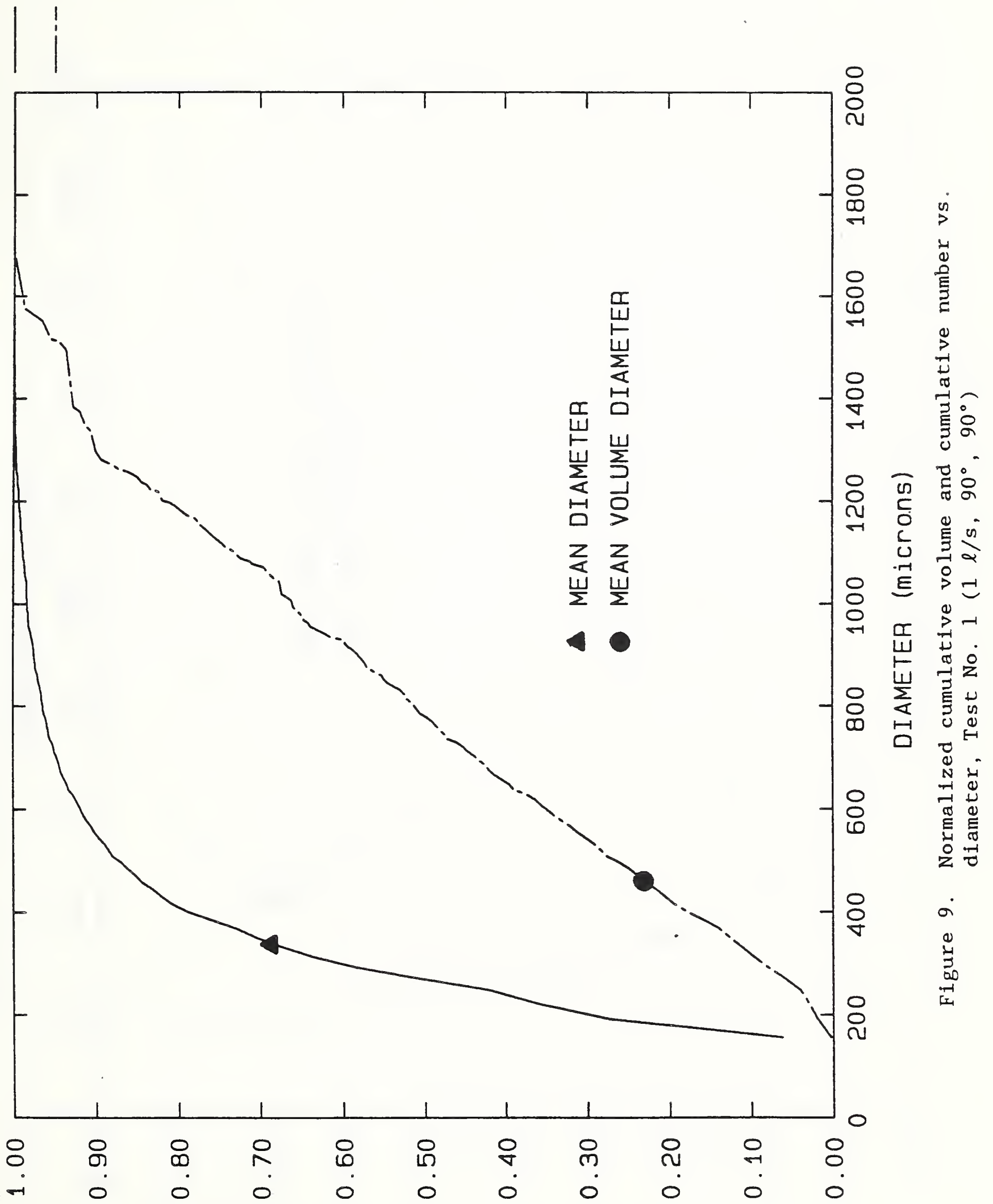

$\exists W \cap า 0 \wedge\urcorner \forall 10 \perp / \exists W \cap า 0 \wedge \quad \exists \wedge I \perp \forall า \cap W \cap ว$

$\forall \exists \boxminus W \cap N \quad 7 \forall 10 \perp / \forall \exists g W \cap N \quad \exists \wedge I \perp \forall 7 n W \cap \supset$ 
釋崖
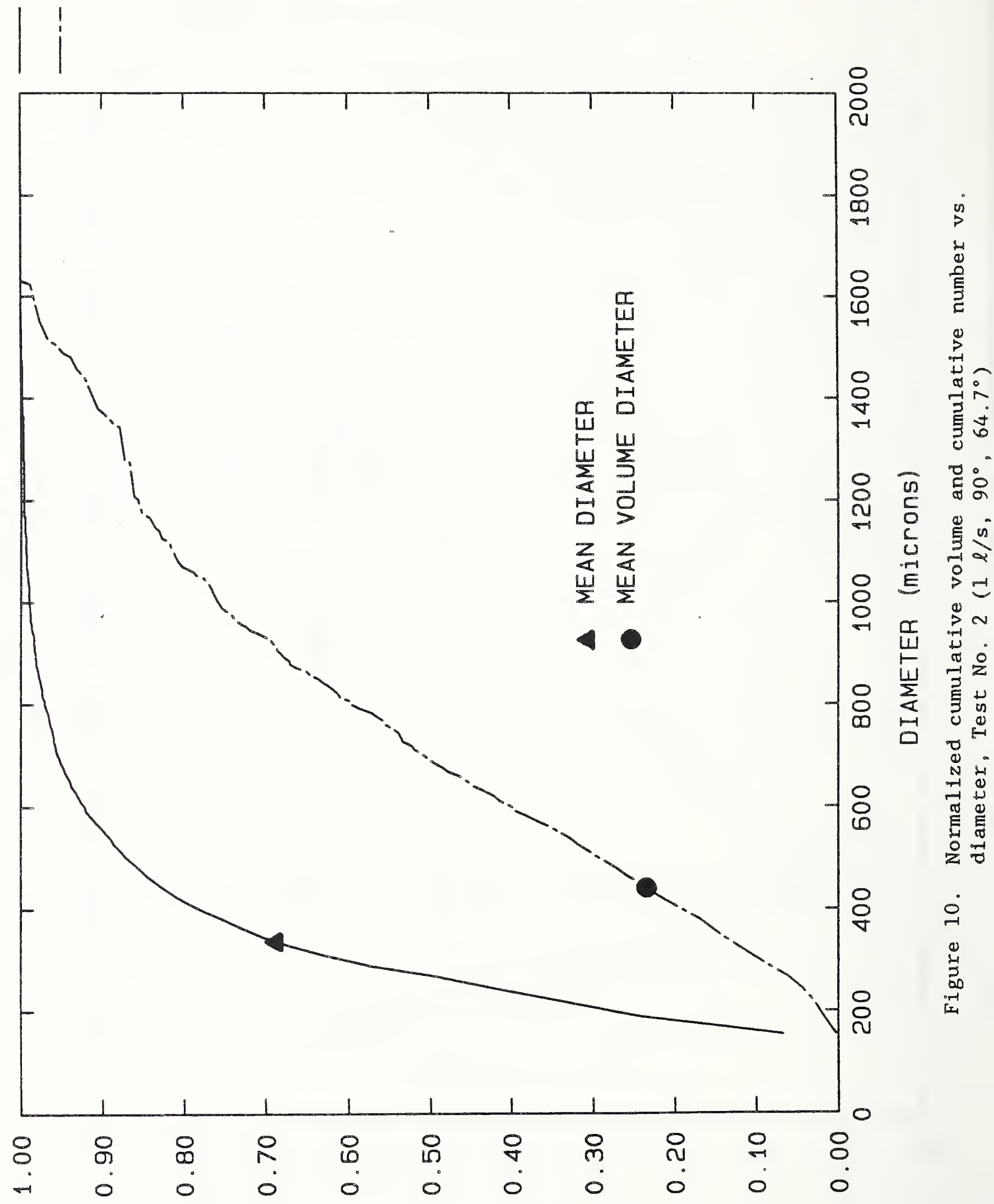

$\exists W \cap 70 \wedge 7 \forall 101 / \exists W \cap 70 \wedge \exists \wedge I \perp \forall า \cap W \cap 0$

$\forall \exists g W \cap N \quad 7 \forall \perp 0 \perp / \forall \exists g W \cap N \quad \exists \wedge I \perp \forall 7 \cap W \cap 0$ 
监崖
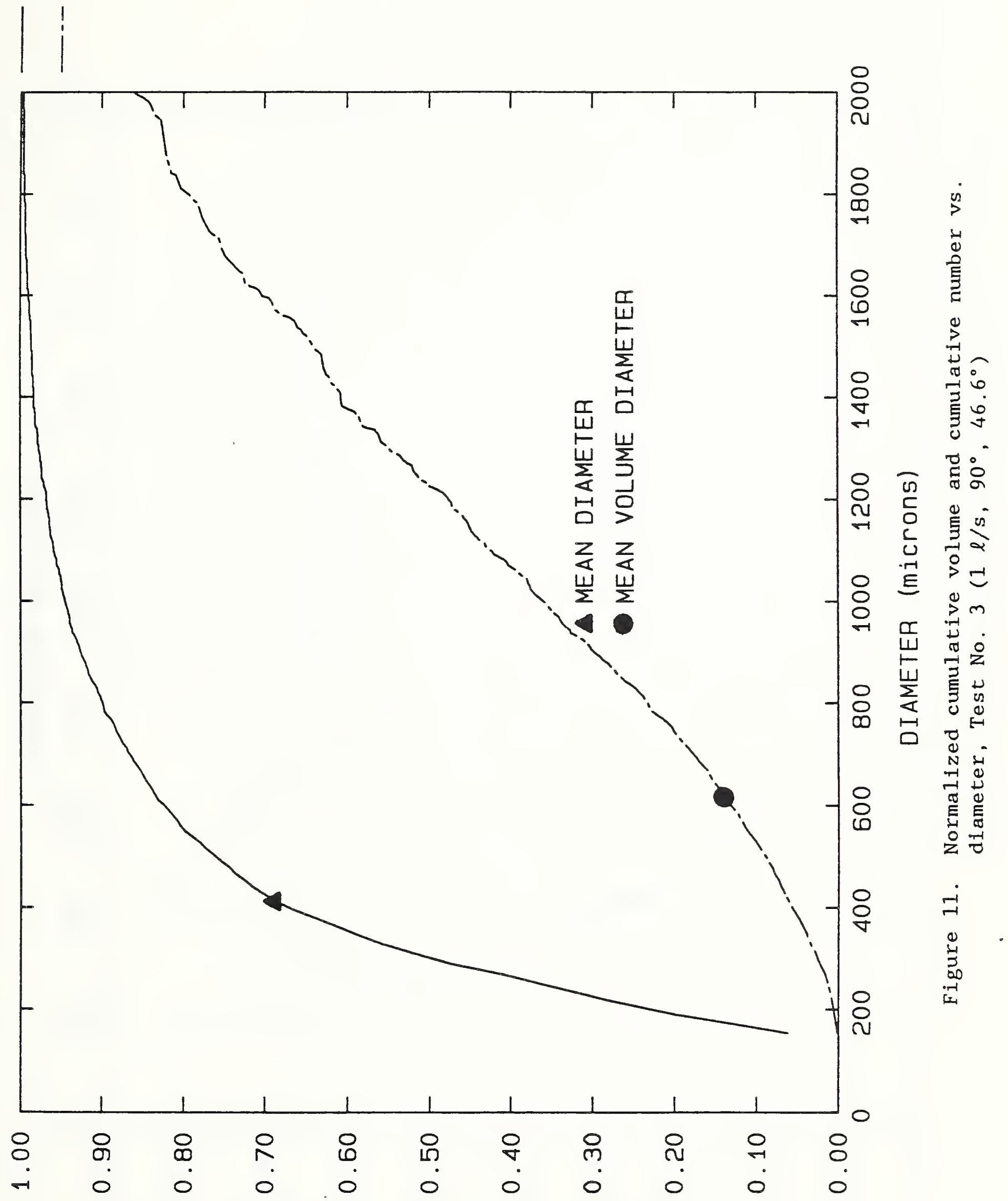

$\exists W \cap 70 \wedge$ ᄀ $\forall \perp 0 \perp / \exists W \cap า 0 \wedge \exists \wedge I \perp \forall า \cap W \cap 0$

$\forall \exists \boxminus W \cap N \quad 7 \forall \perp 0 \perp / \forall \exists g W \cap N \quad \exists \wedge I \perp \forall 7 \cap W \cap 0$ 
釋崖

|

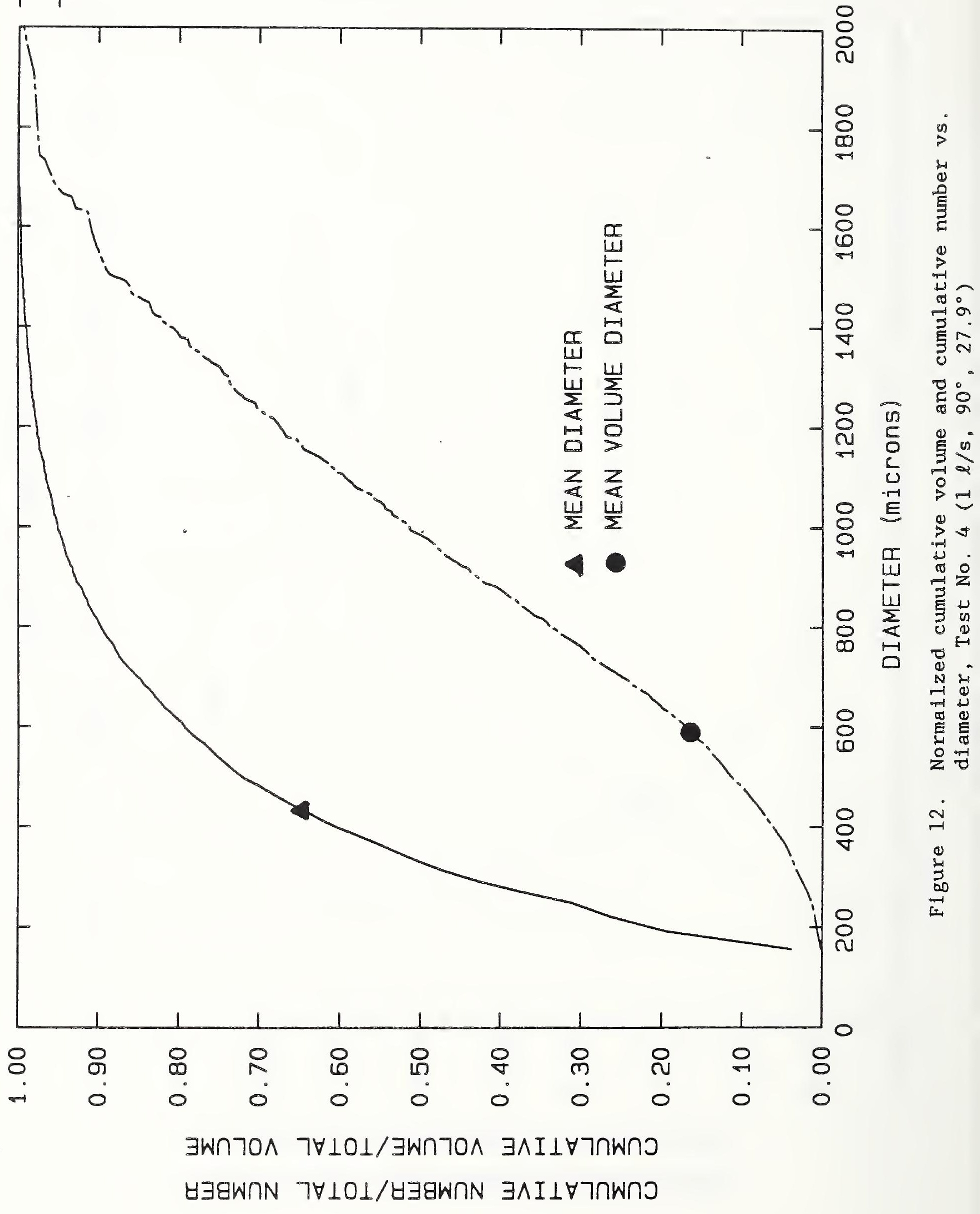


罯崖
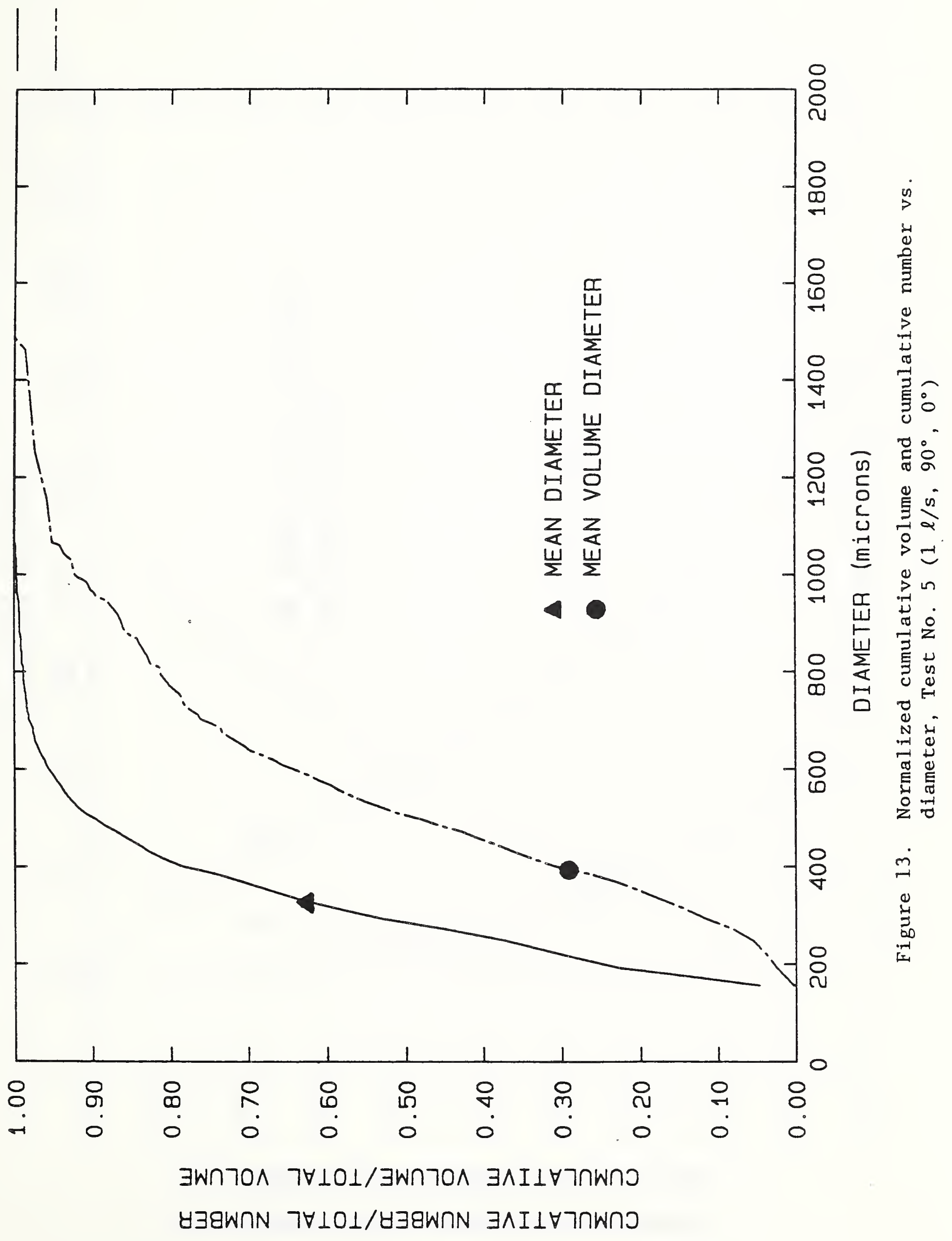

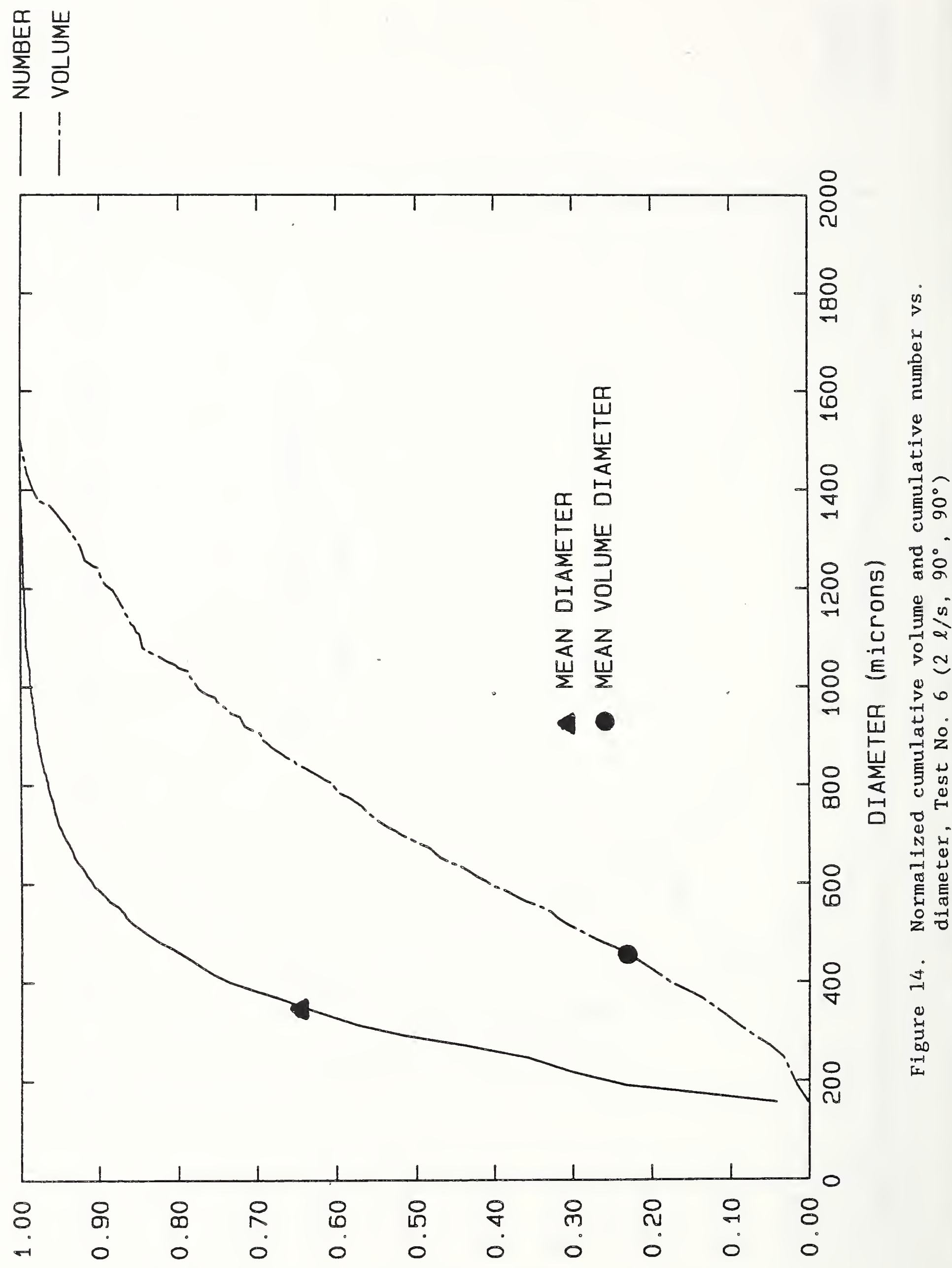

$\exists W \cap 70 \wedge \quad 7 \forall 10 \perp / \exists W \cap 70 \wedge \quad \exists \wedge I \perp \forall า \cap W \cap 0$

$\forall \exists \exists W \cap N \quad 7 \forall 10 \perp / \forall \exists g W \cap N \exists \wedge I \perp \forall 7 \cap W \cap 0$ 


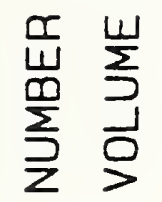

$\exists W \cap า 0 \wedge \neg \forall 10 \perp / \exists W \cap า 0 \wedge \exists \wedge I \perp \forall า \cap W \cap ว$

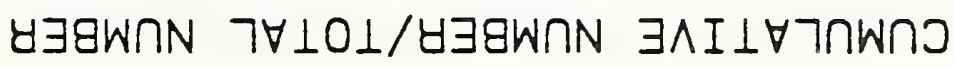


釋崖
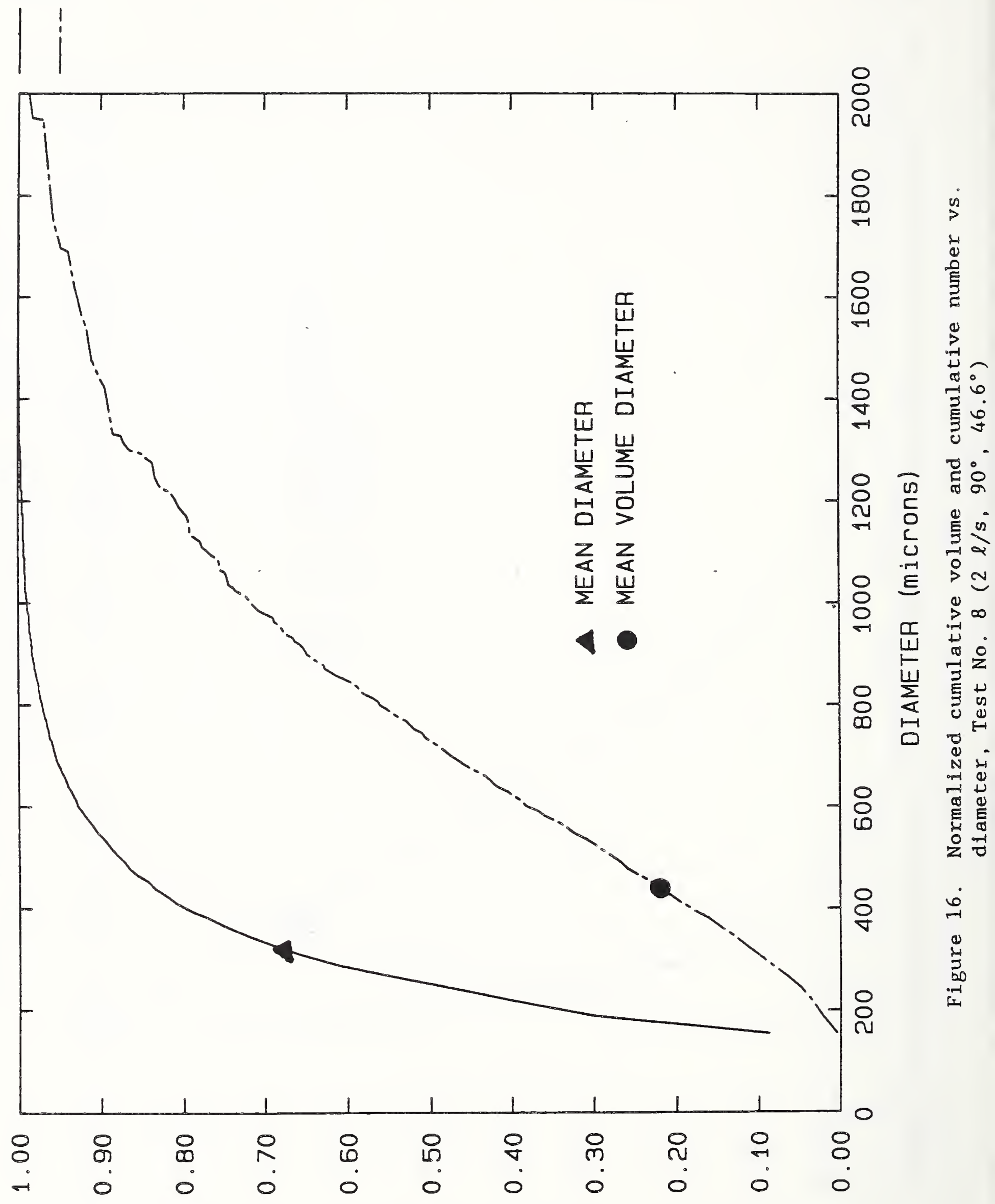

$\exists W \cap 70 \wedge\urcorner \forall 10 \perp / \exists W \cap 70 \wedge \exists \wedge I \perp \forall า \cap W \cap 0$

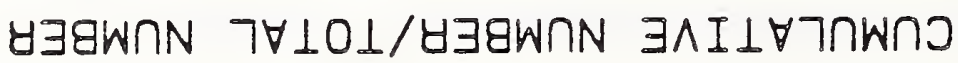




\section{眔崖}
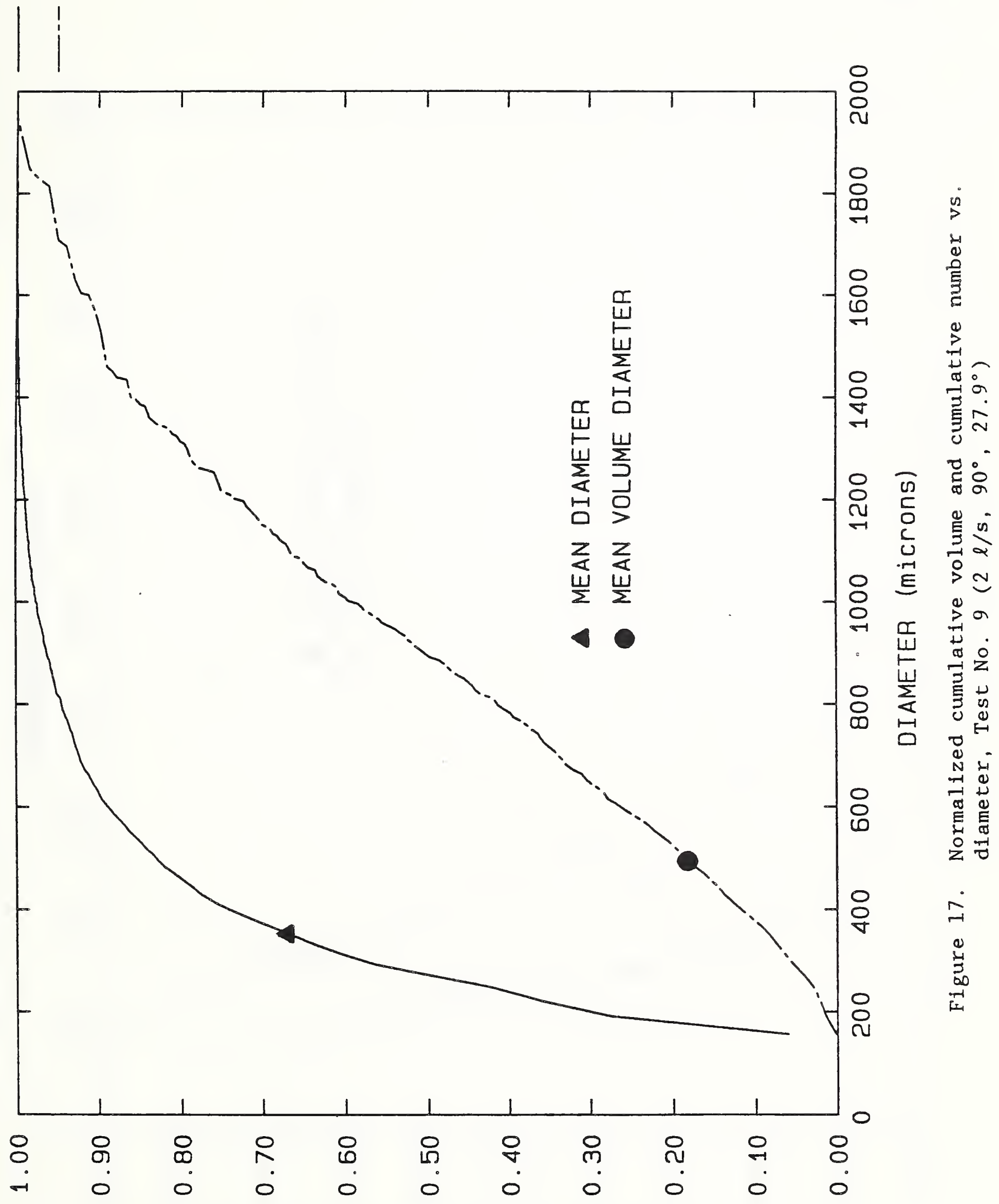

$\exists W \cap า 0 \wedge \neg \forall \perp 0 \perp / \exists W \cap 70 \wedge \exists \wedge I \perp \forall า \cap W \cap ว$

$\forall \exists \Xi W \cap N \quad 7 \forall \perp 0 \perp / \forall \exists \boxminus W \cap N \quad \exists \wedge I \perp \forall 7 \cap W \cap ว$ 


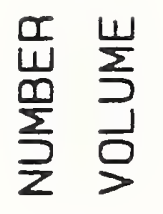

1

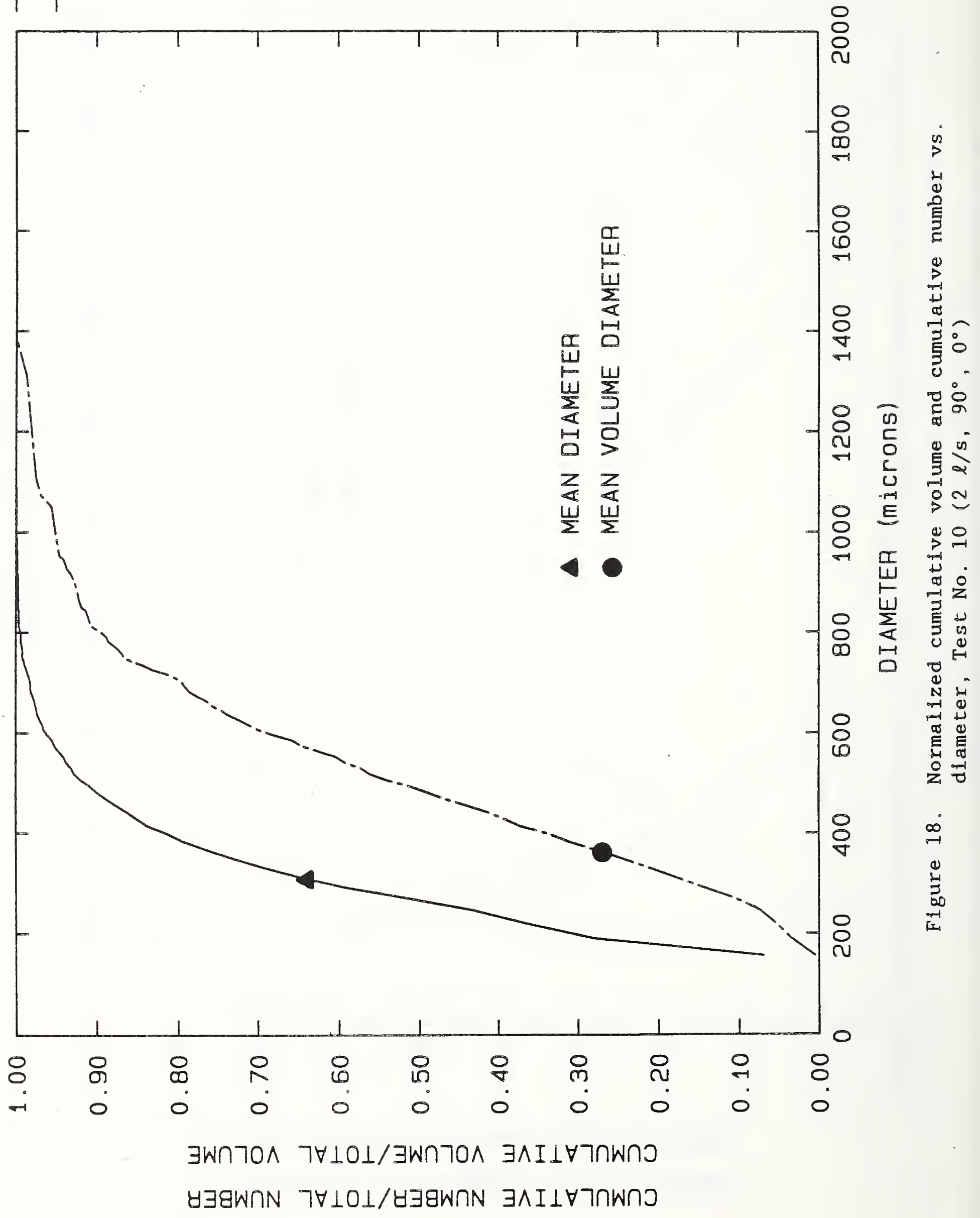




\section{釋崖}
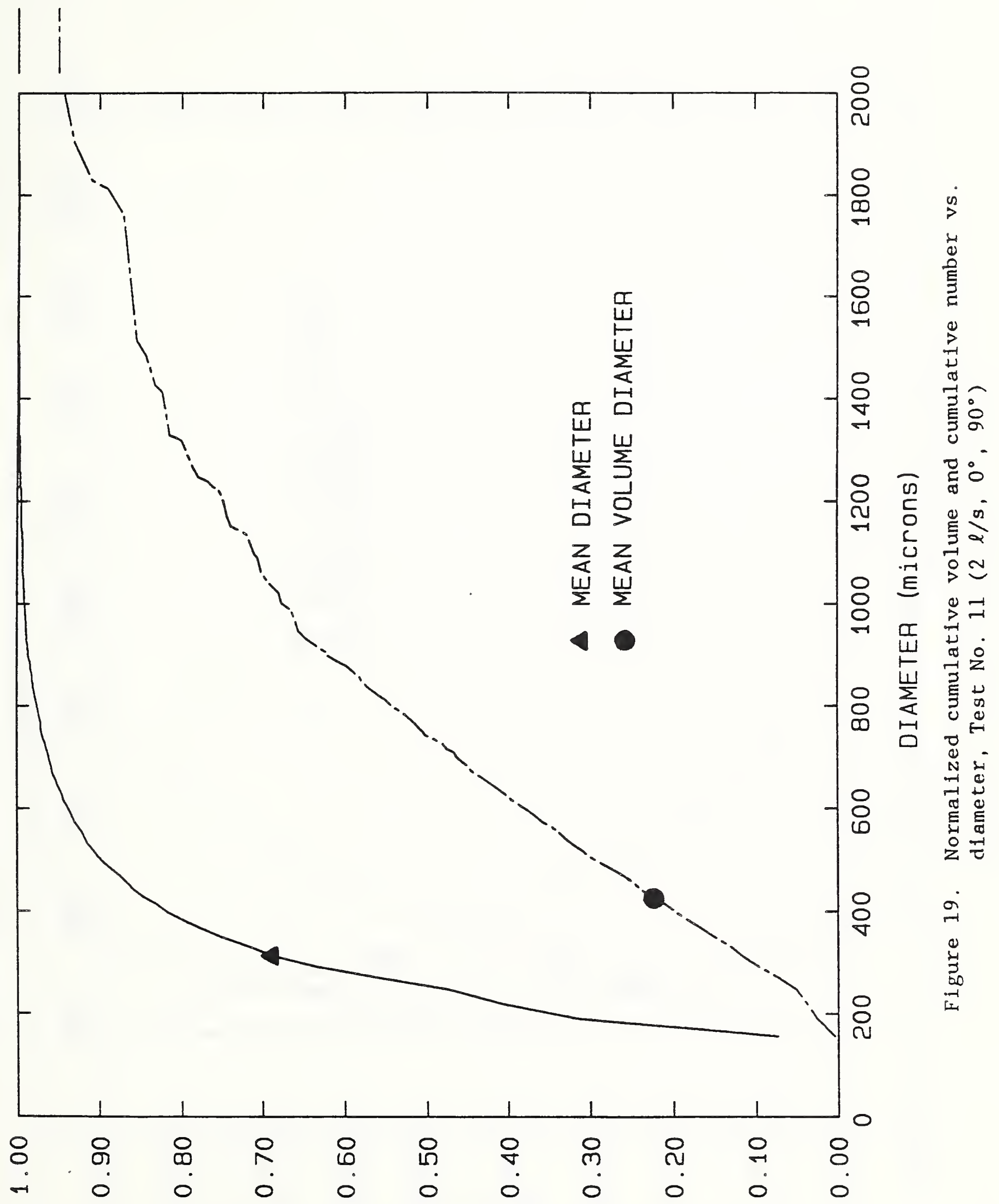

$\exists W \cap า 0 \wedge \neg \forall \perp 0 \perp / \exists W \cap 70 \wedge \quad \exists \wedge I \perp \forall า ก W \cap ว$

$\forall \exists \boxminus W \cap N \quad 7 \forall 10 \perp / \forall \exists \boxminus W \cap N \quad \exists \wedge I \perp \forall 7 \cap W \cap כ$ 
罯峷

11

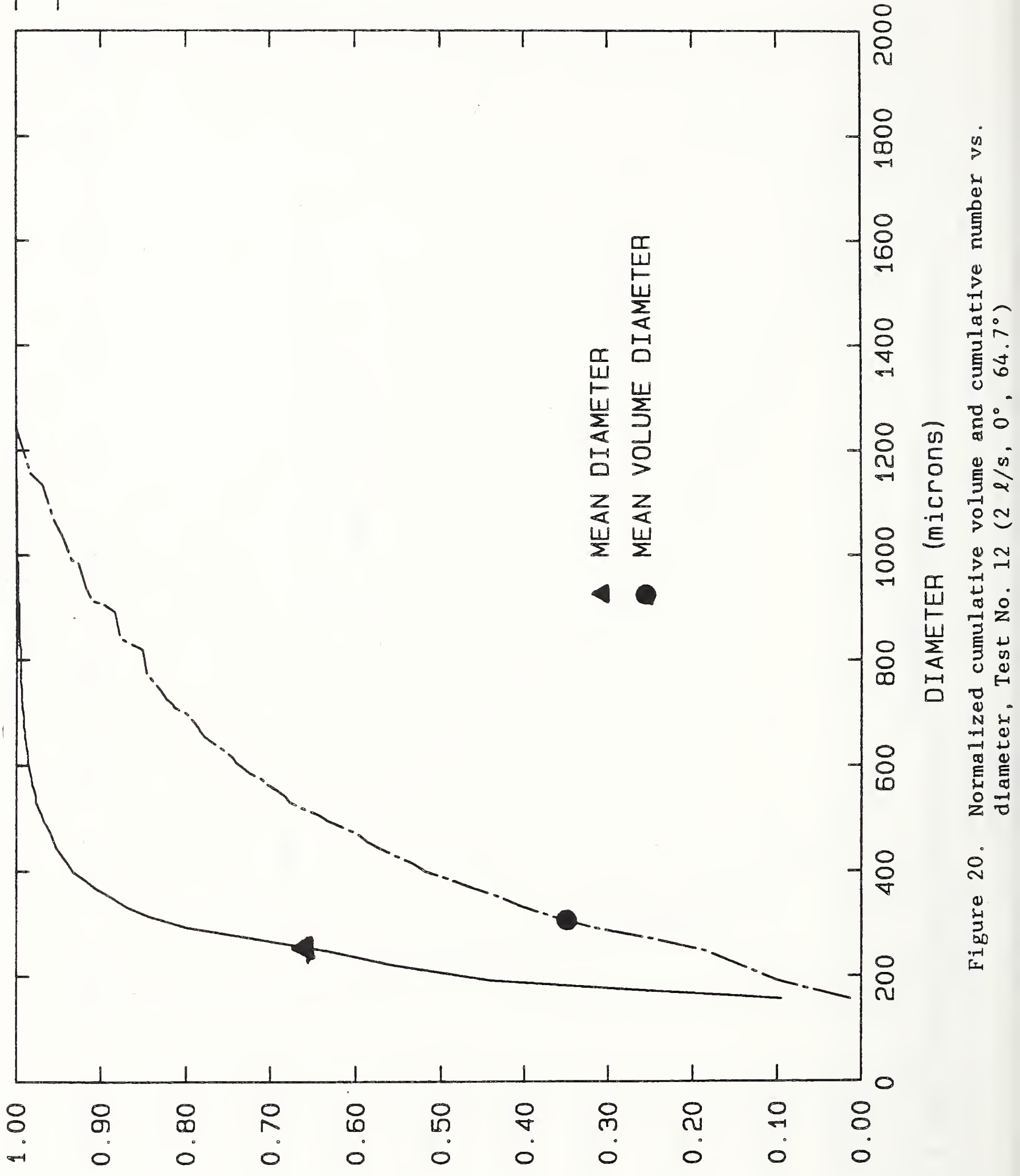

$\exists W \cap า 0 \wedge 7 \forall 10 \perp / \exists W \cap 70 \wedge \exists \wedge I \perp \forall 7 \cap W \cap ว$

$\forall \exists \boxminus W \cap N \quad 7 \forall 10 \perp / \forall \exists \boxminus W \cap N \quad \exists \wedge I \perp \forall 7 \cap W \cap ว$ 


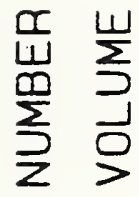
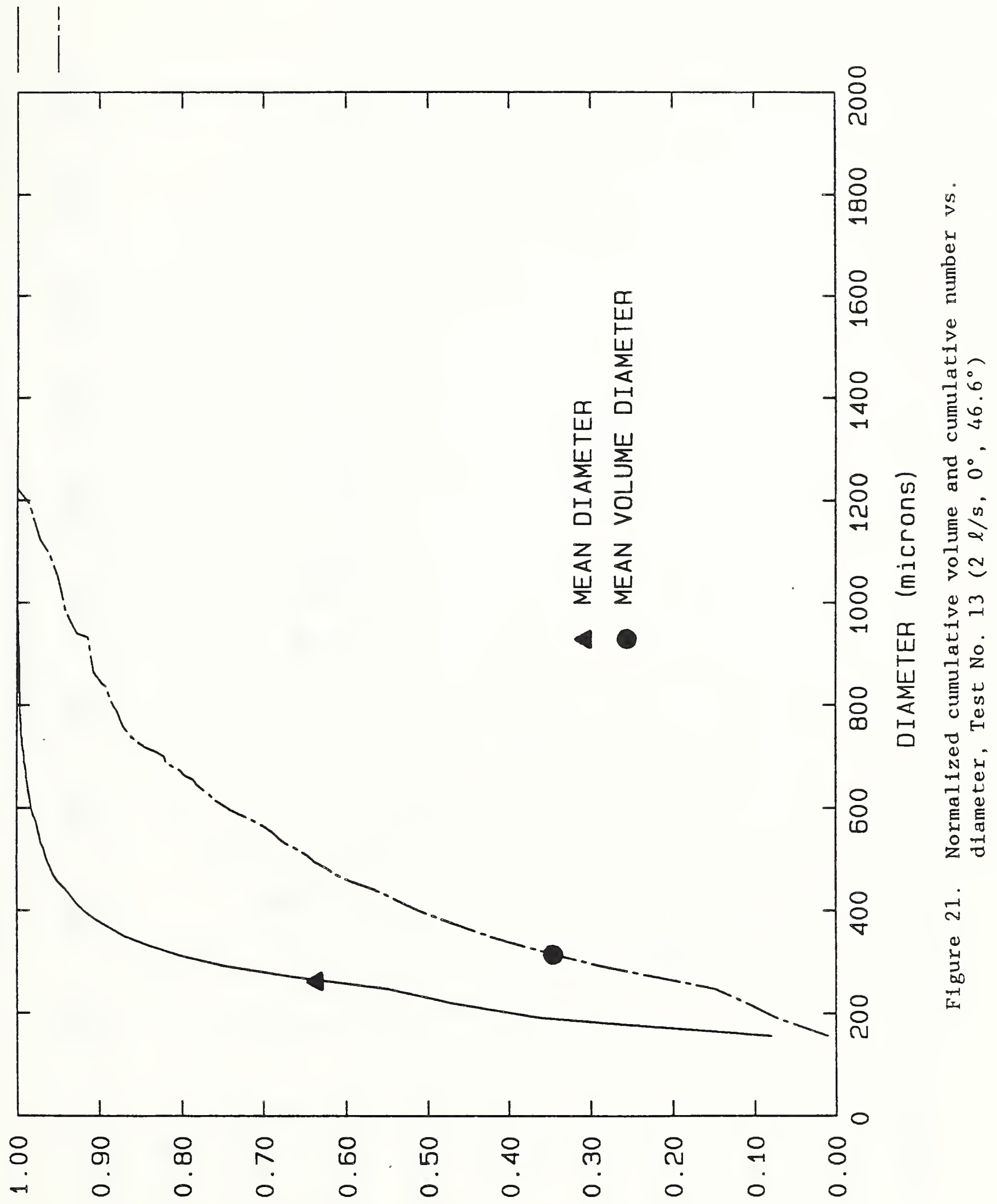

$\exists W \cap 70 \wedge\urcorner \forall 10 \perp / \exists W \cap 70 \wedge \quad \exists \wedge I \perp \forall า \cap W \cap ว$

$\forall \exists \boxminus W \cap N \quad 7 \forall 10 \perp / \forall \exists \boxminus W \cap N \quad \exists \wedge I \perp \forall 7 \cap W \cap J$ 
曙崖
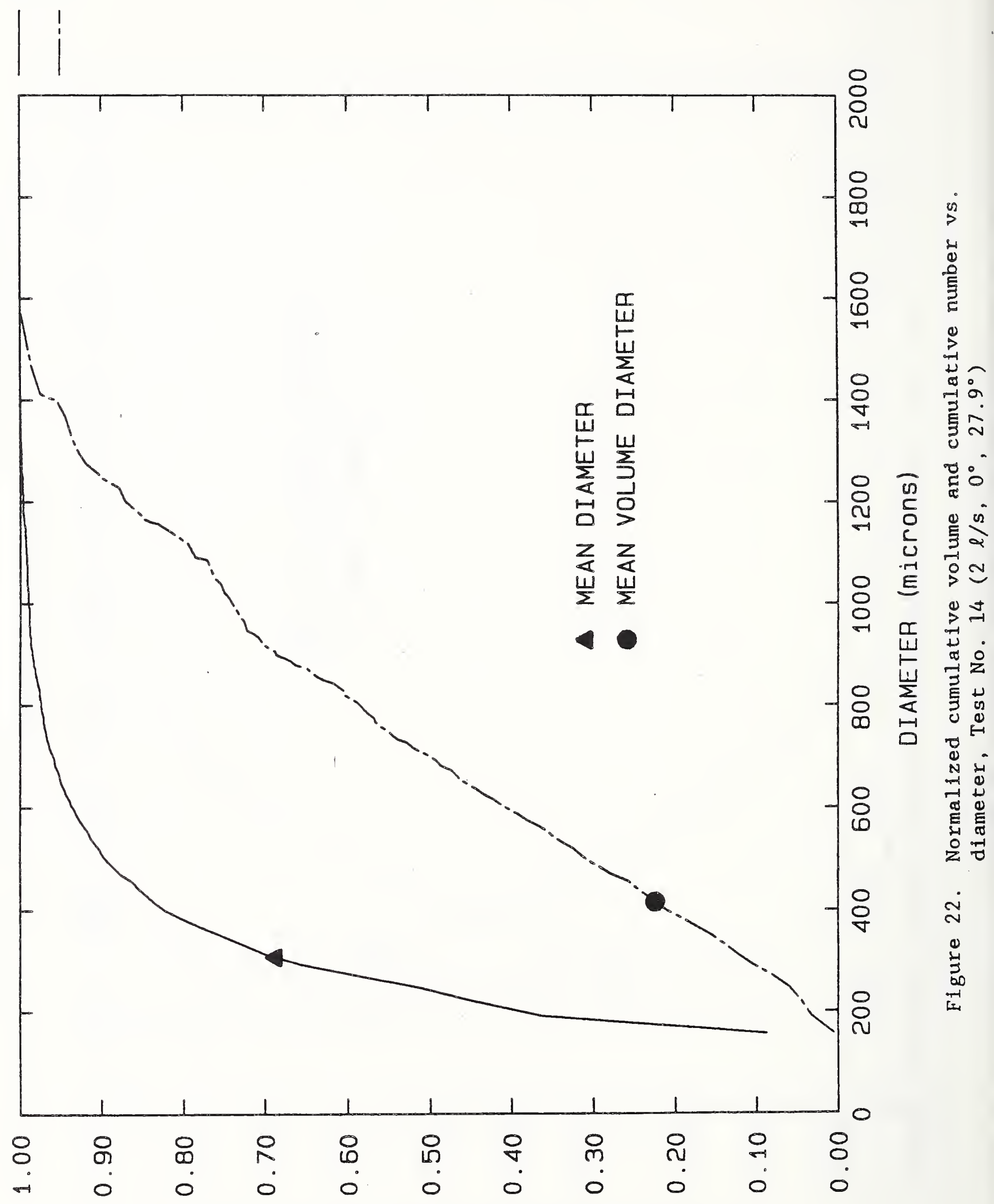

$\exists W \cap 70 \wedge\urcorner \forall 10 \perp / \exists W \cap 70 \wedge \exists \wedge I \perp \forall า ก W \cap ว$

$\forall \exists \boxminus W \cap N \quad 7 \forall 10 \perp / \forall \exists g W \cap N \quad \exists \wedge I \perp \forall 7 \cap W \cap 0$ 
眔崖

|

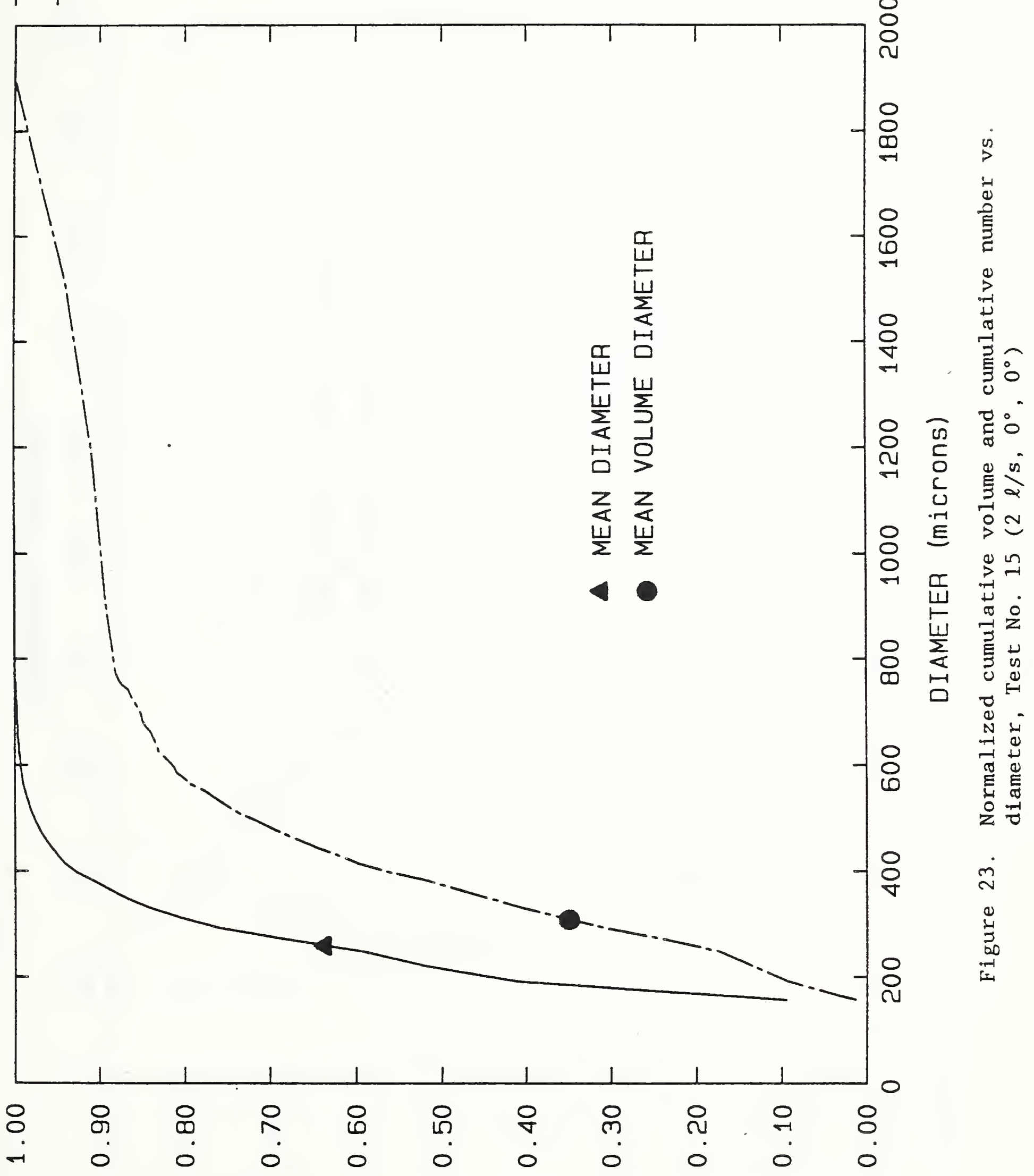

$\exists W \cap 70 \wedge$ ᄀ $\forall 10 \perp / \exists W \cap 70 \wedge \exists \Lambda I \perp \forall 7 \cap W \cap 0$

$\forall \exists \Xi W \cap N$ ר $\forall 10 \perp / \forall \exists \boxminus W \cap N \quad \exists \Lambda I \perp \forall 7 \cap W \cap 0$ 
监峷

11

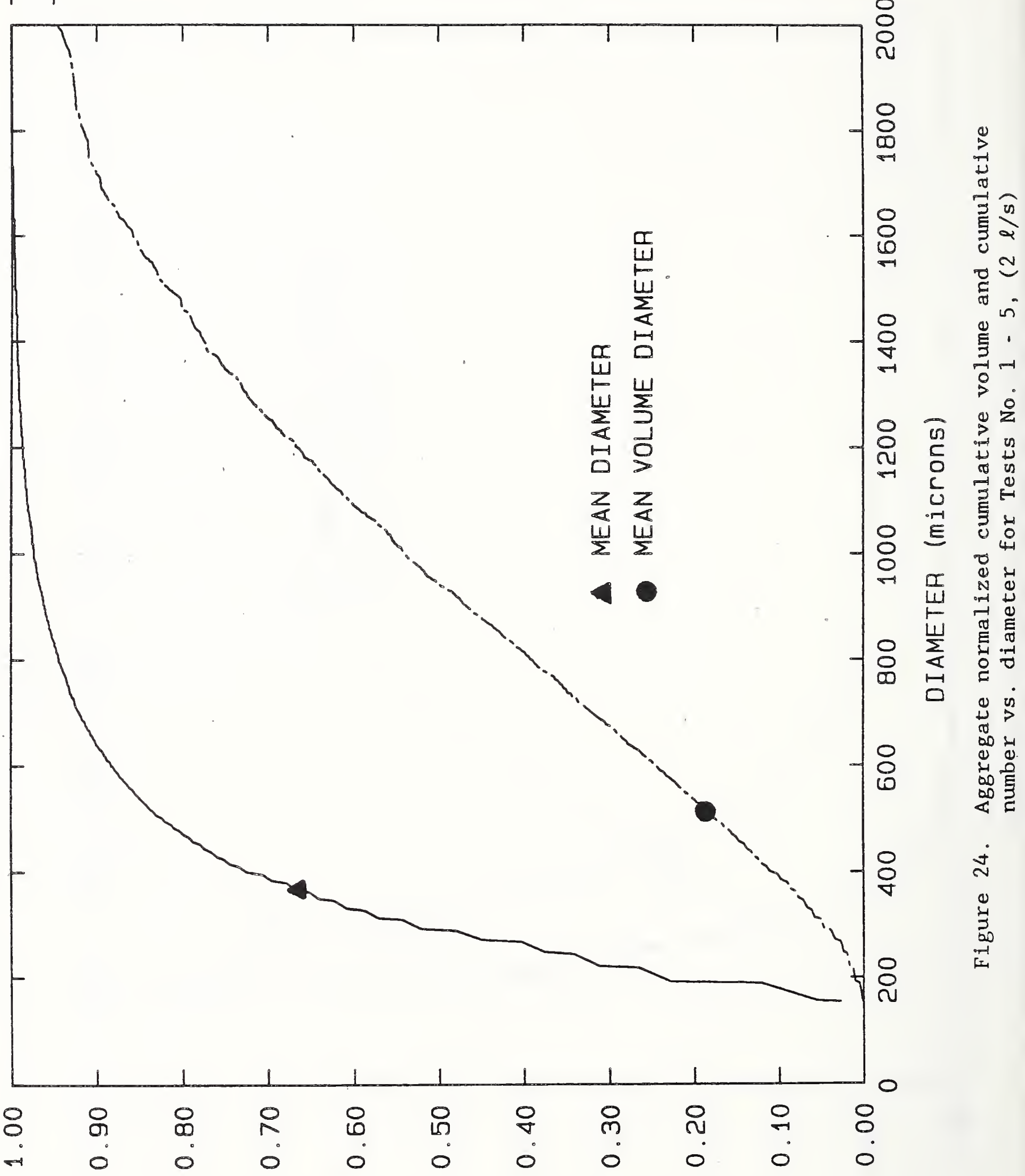

$\exists W \cap 70 \wedge\urcorner \forall 10 \perp / \exists W \cap 70 \wedge \exists \wedge I \perp \forall า \cap W \cap 0$

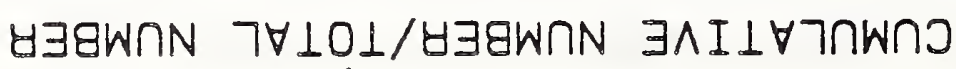




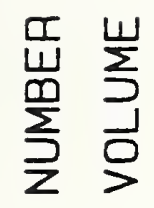

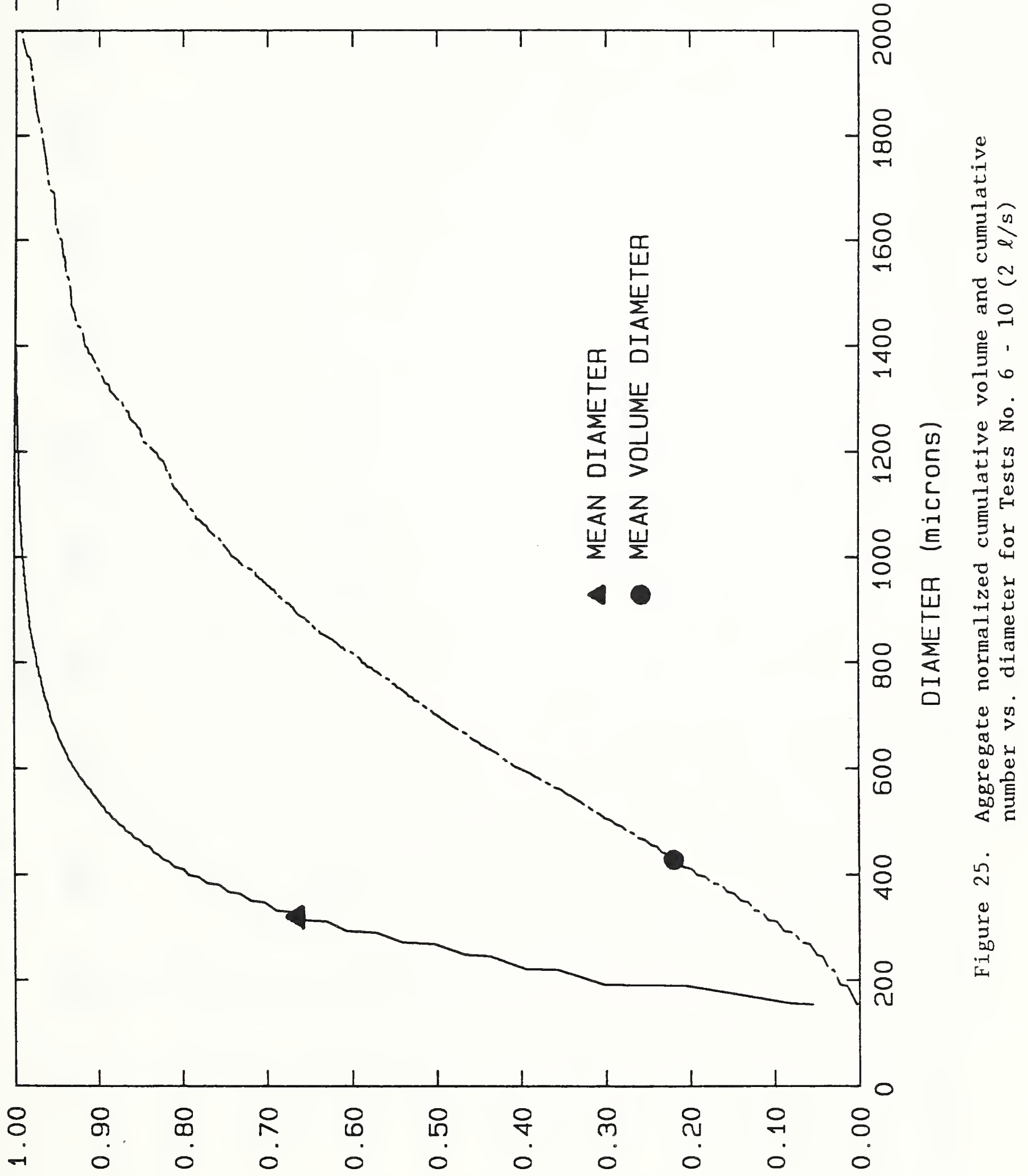

$\exists W \cap า 0 \wedge \neg \forall 101 / \exists W \cap 70 \wedge \exists \wedge I \perp \forall า ก W \cap ว$

$\forall \exists \exists W \cap N \quad \forall 10 \perp / \forall \exists g W \cap N \quad \exists \wedge I \perp \forall า \cap W \cap ว$ 


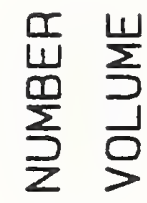

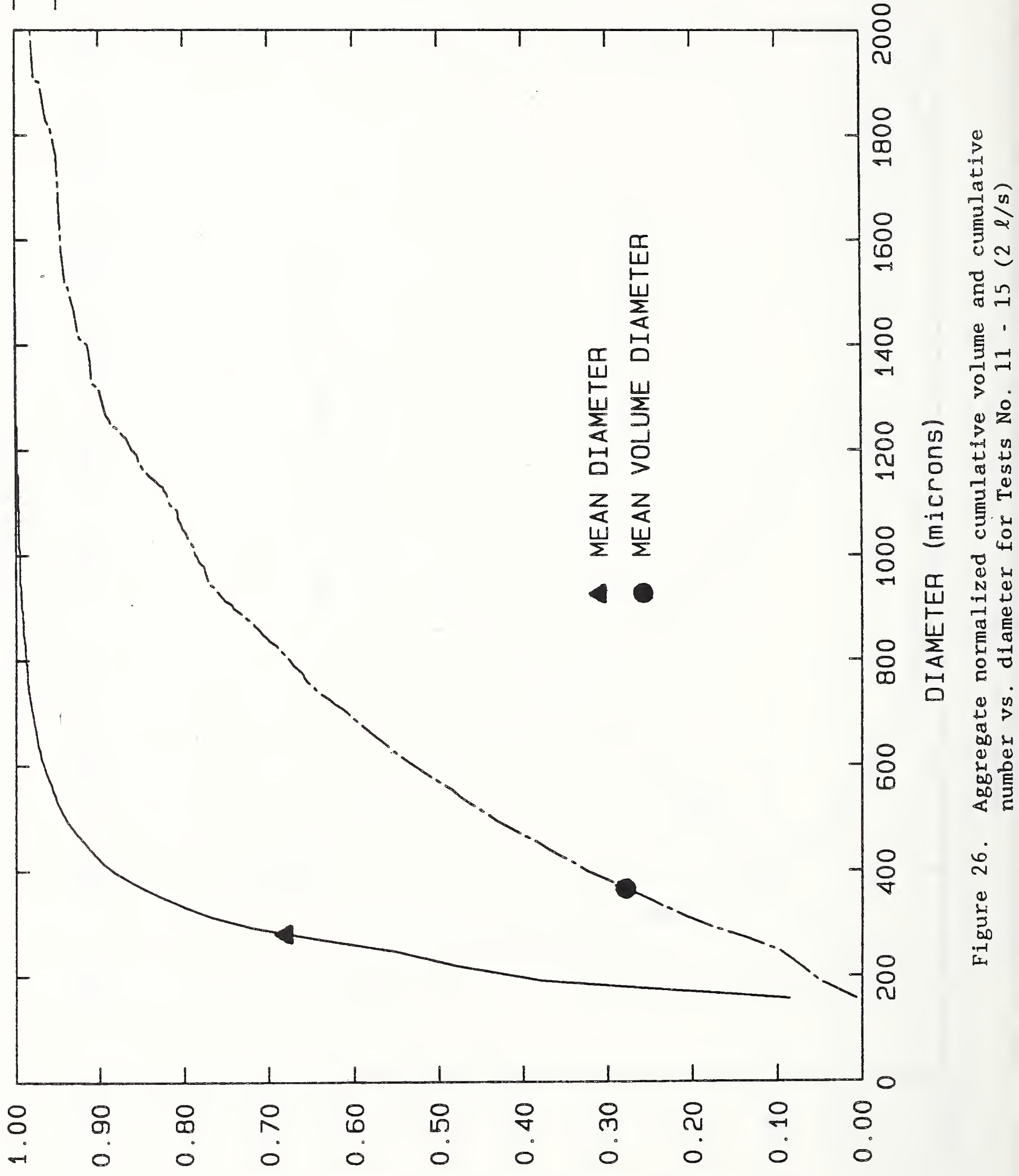

$\exists W \cap 70 \wedge 7 \forall \perp 0 \perp / \exists W \cap 70 \wedge . \exists \wedge I \perp \forall า \cap W \cap ว$

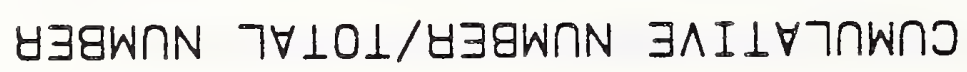




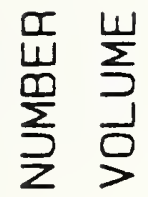
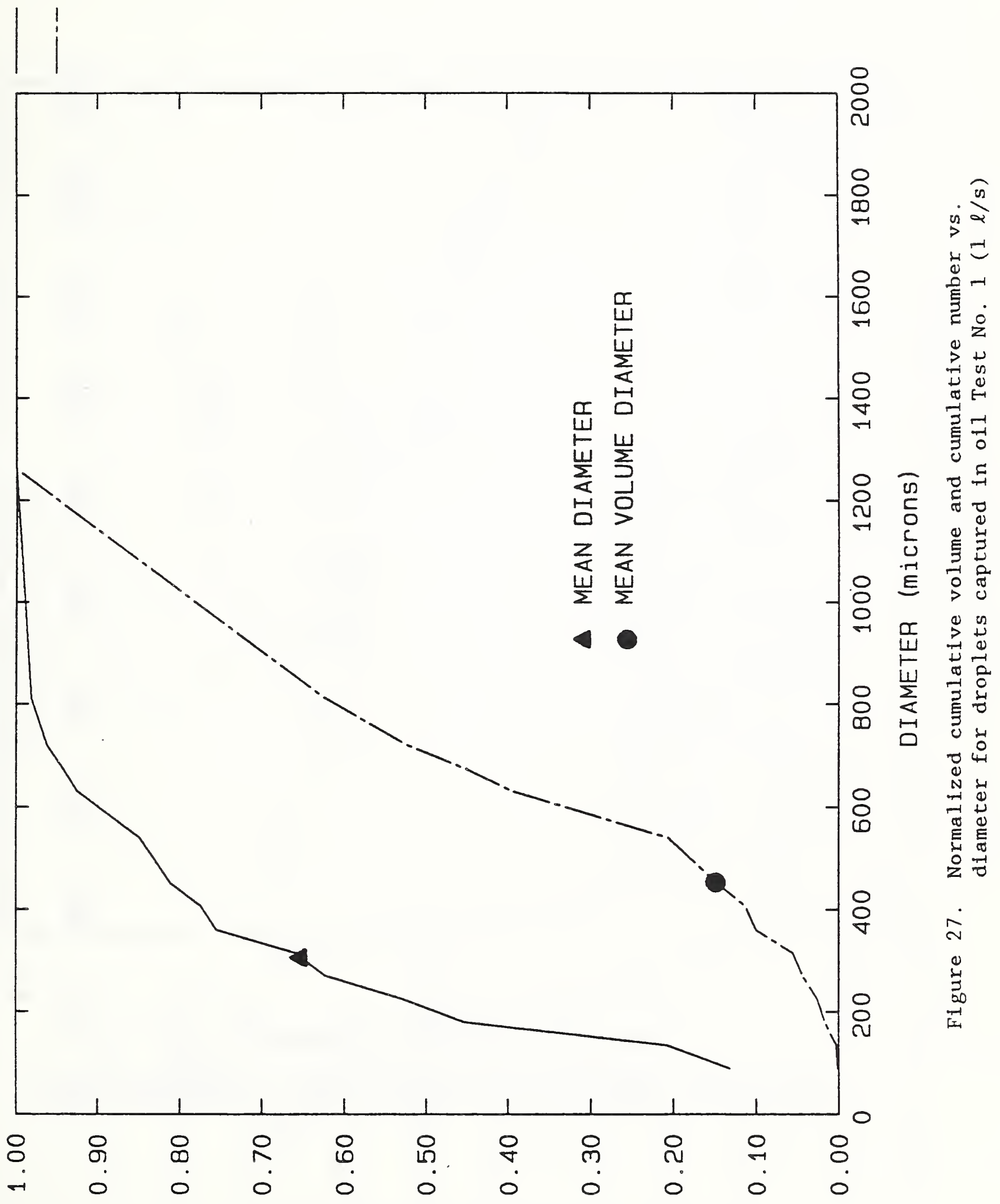

$\exists W \cap า 0 \wedge \neg \forall 10 \perp / \exists W \cap 70 \wedge \exists \wedge I \perp \forall า \cap W \cap ว$

$\forall \exists g W \cap N \quad 7 \forall 101 / \forall \exists g W \cap N \quad \exists \wedge I \perp \forall 7 \cap W \cap \supset$ 
糬崖
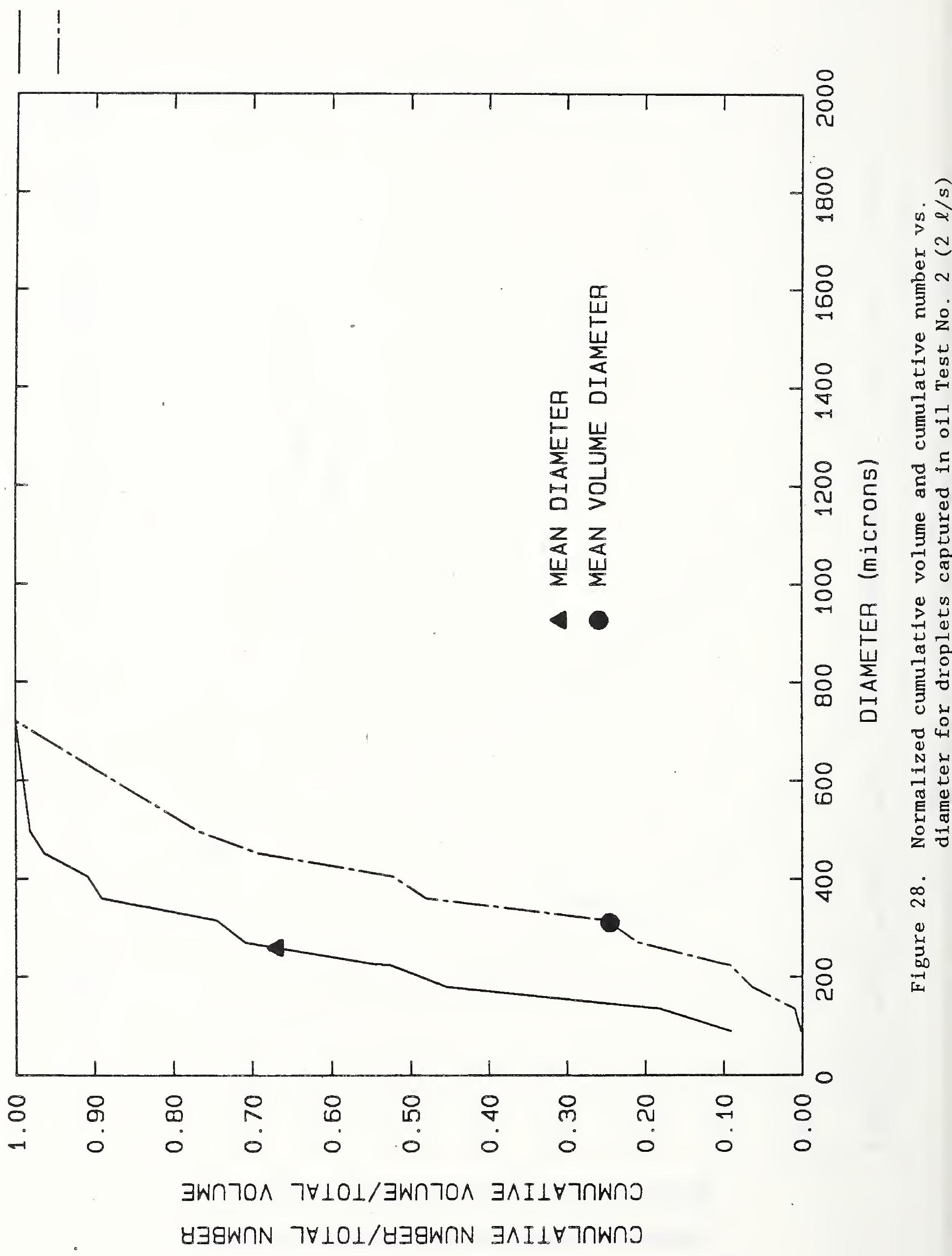


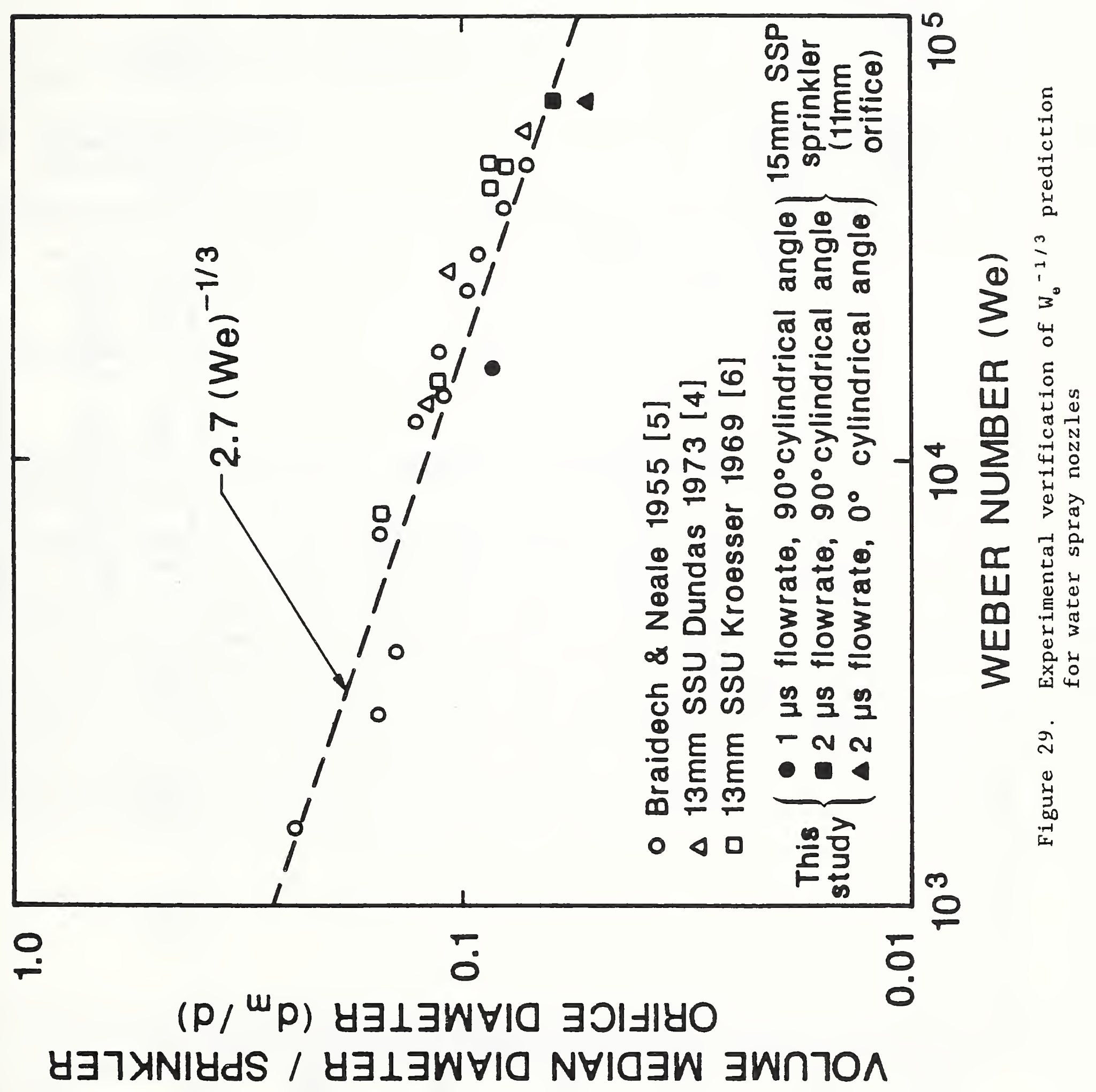




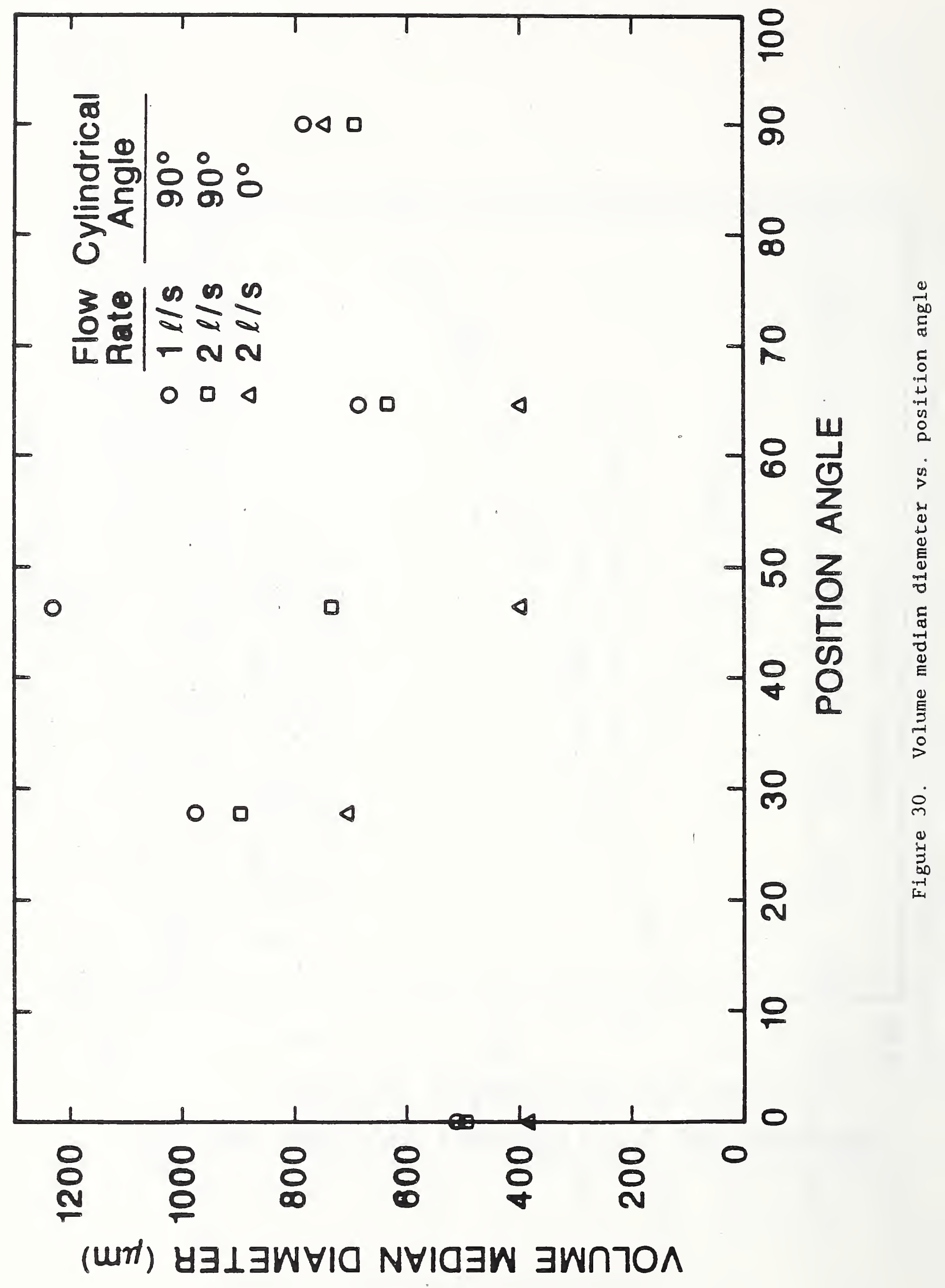


U.S. DEPT. OF COMM.

BIBLIOGRAPHIC DATA

SHEET (See instructions)

1. PUBLICATION OR
REPORT NO.
NBSIR-88/3715

PUBLICATION OR

NBIR-88/3715
2. Performing Organ. Report No. 3. Publication Date

April 1988

4. TITLE AND SUBTITLE

Measurement of Droplet Size in Sprinkler Sprays

5. $A \cup T H O R(S)$

J.R. Lawson, W.D. Walton, and D.D. Evans

6. PERFORMING ORGANIZATION (If joint or other than NBS, see instructions)

7. Contract/Grant No.

NATIONAL BUREAU OF STANDARDS

U.S. DEPARTMENT OF COMMERCE

GAITHERSBURG, MD 20899

9. SPONSORING ORGANIZATION NAME AND COMPLETE ADDRESS (Street, City, State, ZIP)

Swedish Fire Research Board

Stockholm, Sweden

and

General Services Administration Washington, DC

10. SUPPLEMENTARY NOTES

Document describes a computer program; SF-185, FIPS Software Summary, is attached.

11. ABSTRACT (A 200-word or less factual summary of most significant information. If document includes a significant bibliography or literature survey. mention it here)

A computer-controlled video shadowgraph was used to collect data on the spray characteristics of a commercially available sprinkler head. A total of 15 tests were carried out that measured spray characteristics at different positions close to the sprinkler head. Tests were conducted using two different water flow rates, one and two liters per second. Droplet diameters were measured and analyzed to produce graphic presentatiors of normalized cumulative volume and cumulative number vs. droplet diameter data. In addition, a comparison was made between the droplet diameters measured using the video analyzer and droplet samples collected in a light oil and measured manually using a microscope. The data are also compared with results found in the literature. Data on more than 66,000 spray droplets were collected and used for analysis in the development of this report.

12. KEY WORDS (Six to twelve entries; alphabetical order; capitalize only proper names; and separate key words by semicolons) drop size measurements; droplets; water sprays; sprinkler heads; sprinkler systems

13. AVAIL.ABILITY

X Unlimited

For Official Distribution. Do Not Release to NTIS

Order From Superintendent of Documents, U.S. Government Printing Office, Washington, DC 20402.

[X Order From National Technical Information Service (NTIS), Springfield, VA
14. NO. OF

PRINTED PAGES

51

15. Price

$\$ 13.95$ 
